OECDpublishing

COLLABORATIVE

PLATFORMS FOR

INNOVATION

IN ADVANCED

MATERIALS

OECD SCIENCE, TECHNOLOGY AND INDUSTRY

POLICY PAPERS

December 2020 No. 95 
This paper was approved and declassified by written procedure by the Committee for Scientific and Technological Policy (CSTP) on 24 November 2020 and prepared for publication by the OECD Secretariat.

Note to Delegations:

This document is also available on O.N.E under the reference code:

DSTISTP/BNCT(2020)2/REV2/FINAL

This document, as well as any data and any map included herein, are without prejudice to the status of or sovereignty over any territory, to the delimitation of international frontiers and boundaries and to the name of any territory, city or area

(C) $\operatorname{OECD}(2020)$

The use of this work, whether digital or print, is governed by the Terms and Conditions to be found at http://www.oecd.org/termsandconditions. 


\section{Foreword}

This policy report presents findings from the project "Collaborative platforms for innovation in advanced materials" of the OECD BNCT Working Party, Programme of Work and Budget 2019-2020. Delegates, policymakers, and investigators from North America, Europe and Asia developed twelve case studies of collaborative platforms for advanced materials. Edited case studies are included in an Annex to this report.

On 4-5 November 2019, case study authors came together for a two-day workshop in Braga, Portugal, to present their case studies and to discuss key characteristics, challenges and advantages of collaborative platforms for advanced materials in their country-context. The discussions at the workshop and the regular online meetings of the BNCT Advanced Materials Steering Group enabled the presentation and comparison of case studies. Work on the report continued through interactions between the project steering group and the Secretariat.

The contributions of the BNCT Advanced Materials Steering Group are gratefully acknowledged, particularly the following members (in alphabetical order by country): Stefanie Prenner (Brimatech/Austria), Johanna Berndorfer (Brimatech/Austria), Phil de Luna (National Research Council/Canada), Jun'ichi Sone (Japan Science and Technology Agency), Chan-Woo Lee (Korea Institute of Energy Research), Luís Viseu Melo (BNCT delegate/Portugal) and Lisa Friedersdorf (National Nanotechnology Coordination Office/United States).

The additional financial support of Austria and Canada for this project is gratefully acknowledged. 


\title{
Collaborative platforms for innovation in advanced materials
}

\author{
Laura Kreiling*, Douglas K. R. Robinson**, David Winickoff*
}

Abstract

This report draws on evidence from 12 case studies to characterise the governance mechanisms of collaborative platforms for advanced materials - including terms of funding, access, and IP policy - and explores under what conditions they can produce tangible and intangible value. Advanced materials hold significant potential to improve products and production processes, yet realising their promise remains challenging: it has historically taken 15 to 20 years from the discovery of new materials to their deployment. Consequently, governments have been creating collaborative platforms - shared digital and physical infrastructures - to pool and manage global data, drive the development of nascent industries, and create hubs of interdisciplinary research, development and training. This study identifies technology convergence, the engagement of society and digitalisation as key trends in the field; it also describes conditions under which collaborative platforms can construct value chains, foster standards, catalyse innovation ecosystems, and build skills and social capital.

Keywords: collaborative platforms, advanced materials, governance mechanisms, case studies, innovation policy

* OECD

** CNRS/ Université Paris-Est Marne-la-Vallée 


\section{Executive summary}

Advanced materials hold significant potential to create better products and production processes, and governments are currently experimenting with the creation of shared digital and physical infrastructures in order to enable their development. These "collaborative platforms" are expected to become sustainable by making their facilities and services accessible to industry and by attracting a community of users, investors and other stakeholders.

- Collaborative platforms promise to build collective advantage by addressing major challenges in modern materials science today. These include:

- the global scale management of material data, providing infrastructure for the pooling of data, the need for scalable data repositories and data curation strategies;

- the removal of redundancy and the co-location of instrumentation and technical skills;

- powering new product development and nurturing nascent industries by coordinating value chains that drive technical standards and connecting the supply and demand sides of technology markets; and

- creating hubs of interdisciplinary research, development and training.

In order to realise these critical functions, collaborative platforms must be well-designed in terms of governance (e.g. issues around IP, data access and privacy). In this regard, many important policy questions face policymakers, funders, scientists, business leaders and the public in this field. To what extent and how should collaborative platforms pool digital and physical infrastructure? How can they power innovation ecosystems and exploit technology trends? What are the mechanisms through which they coordinate diverse actors and connect supply and demand sides of technological markets? In short, how can they best enable the development and commercialisation of new advanced materials, and foster the development of products and businesses?

Collaborative platforms for advanced materials are diverse. They involve different types of stakeholders, different mixes of public and private actors and may focus on catalysing activities at different market stages. They can act as a nexus between disciplines, creating hubs of interdisciplinary research and development. Such interdisciplinary nodes can be a resource, for example, where the convergence of expertise from different fields can benefit users of the platforms in their individual projects.

Sustainability of the enterprise is a universal concern, which places high importance on business models. Three interrelated elements of the business models of collaborative platforms take central importance: funding structures, access models, and intellectual property (IP). These elements represent policy choices and levers for building and sustaining diverse kinds of value. Different platform types rely on direct government support to differing degrees. Collaborative platforms handle access in diverse ways, but could be divided into two models: (1) membership and (2) open access models. Fees, for instance, can be a barrier for platform participation for some stakeholders, especially for SMEs or academic units. From SMEs to larger firms, participants must see value in using the platform and mechanisms must be found to encourage participation and investment. IP is a core aspect for the implementation and running of a collaborative platform.

Three forms of coordination are particularly striking with regards to market formation and the development of industries-in-the-making: (1) collaborations for aligning and powering 
value chains for new advanced material options, (2) orchestrating the development of technical and data standards and (3) engaging with local innovation ecosystems. Collaborative platforms can develop and connect value chains for new advanced material options thereby functioning as support systems for the technology readiness journey of a novel material. Further, collaborative platforms can shape markets by fostering standards, regulation and good practices. Technical standards, for example, constitute a form of market infrastructures since they are necessary for quality control, interoperability and to support regulation. Collaborative platforms for advanced materials development play a key role in the development and testing of standards in their various forms.

Key challenges for data sharing in the field of advanced materials include expertise, cost, proper data curation processes, proprietary information and the lack of incentives for companies to do so. Governments could play a vital role by linking public funding with data sharing.

Collaborative platforms can act as both a hub and a compass for innovation ecosystem actors, outside of customised contractual agreements between parties. Another key strength and potential for collaborative platforms is to build skills and develop human capital. Education and workforce development are critical components of a number of the platforms studied.

For advanced materials, there are three key trends that are shaping the nature, impact and policy support of collaborative platforms. These trends present both challenges and opportunities for leveraging collaborative platforms to enable advanced materials.

1. The first lies in "convergence": the greater integration of research, industry and societal actors, the transformation of knowledge across technology development stages and the multiple science and technology disciplines that deliver platform projects. Triggering new ideas, methods and outputs of collaborative platforms for advanced materials, convergence should be enhanced to drive innovation.

2. The second trend focuses on the increasing importance of engaging the wider society. Collaborative platforms are tools of choice for developing and improving scientific culture in society by acting as focal points of communication with the public about respective technologies and their potential application in day-to-day life. Engaging with a broad array of actors, publics and policy makers, they are also well-positioned to better align technological development with societal needs and key challenges, such as food security, climate change, artificial intelligence and automation, the future of work, etc.

3. The third trend is a development in how digitalisation is engaging and shaping the nature of collaborative platforms. Here, the realisation of the potential of digitalisation in the field of advanced materials will require:

- building high quality databases, which requires a common format for the data and the metadata and transforming these data provided by researchers into the standardised data format.

- creating incentives for individual researchers to provide data to such platforms.

- co-developing data analysis tools using data science and informatics to find the relationship of materials structure and property/function, and to find optimum materials. 


\section{Table of Contents}

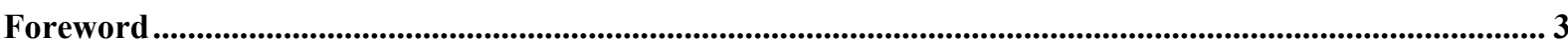

Collaborative platforms for innovation in advanced materials...................................................................4

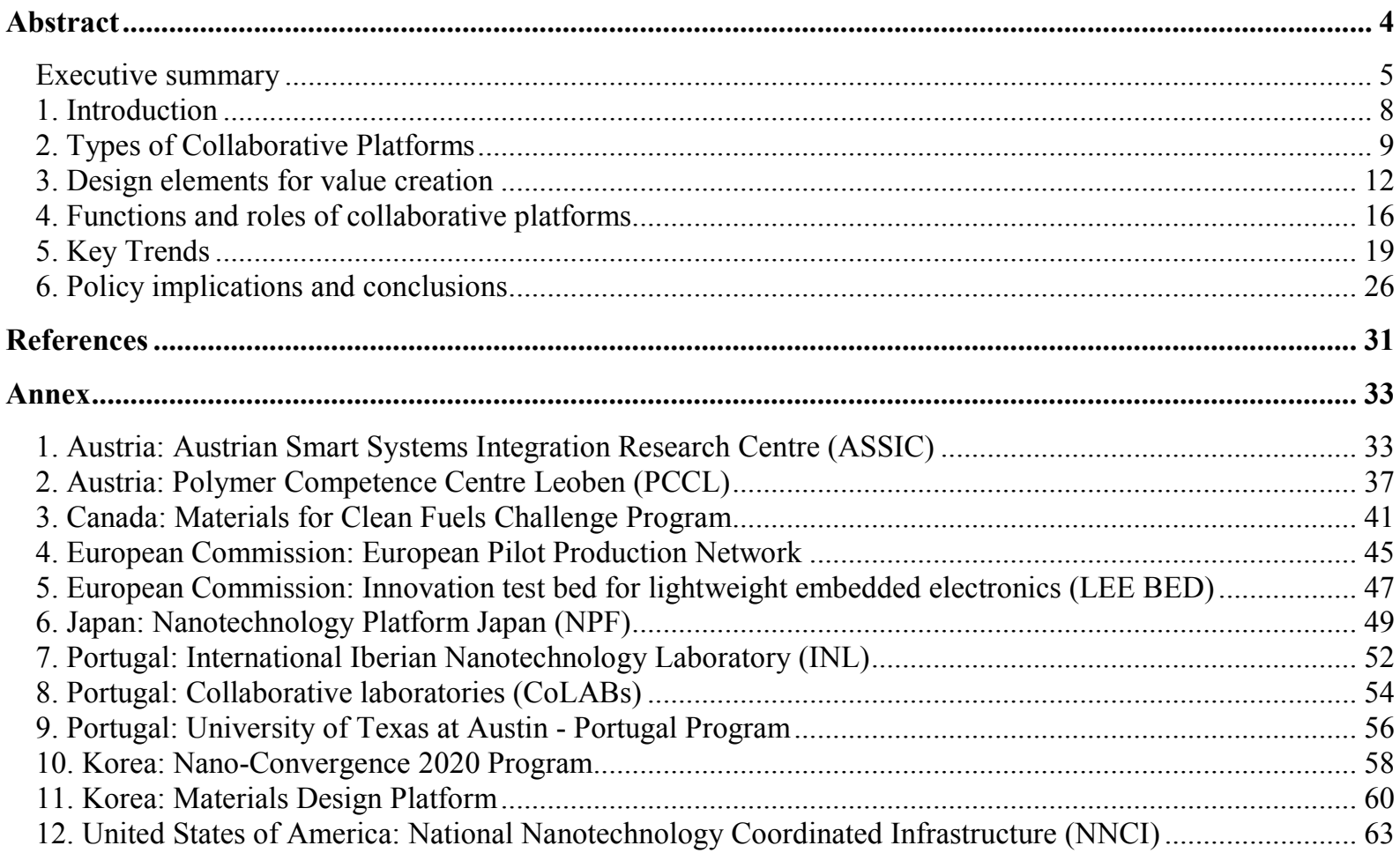

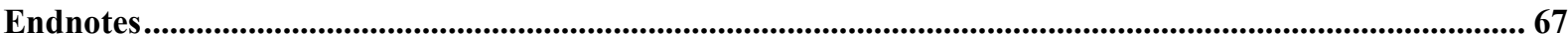

\section{Tables}

Table 1. Definition of Terminology Regarding Outcome Measures of the Nano-Convergence 2020 Program.... 59

\section{Figures}

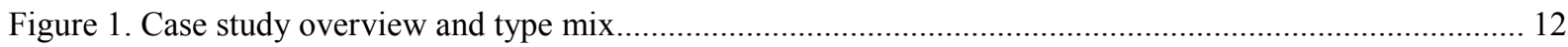

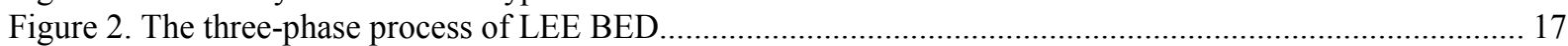

Figure 3. Schematic overview of convergence in advanced materials collaborative platforms ......................... 20

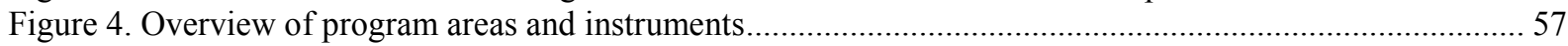

\section{Boxes}

Box 1. Example of a Type 1 platform - the National Nanotechnology Coordinated Infrastructure (NNCI) ........ 10 Box 2. Example of a Type 2 platform - the Austrian Smart Systems Integration Research Centre (ASSIC) ....... 11 Box 3. Example of active IP leveraging by a platform - the Korean Nano-convergence platform ..................... 16 Box 4. Examples from the United States - Integrating societal dimensions of technologies in platforms ........... 22 Box 5. Examples from Canada - Collaborative platforms as tools to address societal challenges ......................24 Box 6. Example of a Type 3 platform - the Korean Material Design Platform ............................................. 26 


\section{Introduction}

The world urgently seeks pathways towards a sustainable future, and emerging technologies will necessarily be part of the answer. Advanced materials is a key field in this regard, promising new and efficient materials as well as improved production processes. Yet realising the promise of advanced materials remains challenging. Historically it has taken 15 to 20 years from laboratory discovery of new materials to their deployment in products. Currently, advances in scientific instrumentation, computing and predictive computational methods for material structure and properties, and data analytics are catalysing materials discovery and development. Increasing the rate of discovery and development of new and improved materials is key to enhancing product development and facilitating mass customisation based on emerging technologies such as $3 \mathrm{D}$ printing. In a context of great urgency, how can this process be accelerated?

This paper focuses on how "collaborative platforms" can drive innovation in advanced materials. Governments are currently experimenting with the creation of shared digital and physical infrastructures and access to technology and services in order to expand their capacity to develop advanced materials beyond scientific research. These platforms are expected to become sustainable by making their facilities and services accessible to industry and by attracting a community of users, investors and other stakeholders. Collaborative platforms must be well-designed in terms of organisation and operation, but also in terms of governance (e.g. issues around intellectual property (IP), data access and privacy). Trends such as digitalisation are creating new efficiencies and new opportunities for collaboration and co-innovation.

Platform-based infrastructures promise to enable the convergence of a diverse range of fields, such as materials data science and informatics, molecular biology, chemistry and artificial intelligence; and to allow the research enterprise to better engage with the private sector as well as broader publics. Innovation is increasingly shifting towards platformbased ,e.g. Gawer, $\left(2014_{[1]}\right)$; Katz and Shapiro, (1994 $\left.{ }_{[2]}\right)$, physical and/or digital infrastructure in which diverse public, private, and non-profit agents engage to innovate jointly or individually. These "collaborative platforms" carry great potential for catalysing innovation and for translating these technologies into markets and society.

Many important policy questions face policymakers, funders, scientists, business and the public in this field. To what extent and how should collaborative platforms pool resources to make it easier to provide capabilities that otherwise may not be readily available? How can they be better designed to anchor innovation ecosystems, power new product development, and exploit technology trends? What are the mechanisms through which they coordinate participants and facilitate connections between the supply and demand sides of technological markets? In short, how can they best enable nanotechnology-driven solutions, and foster the development of products and businesses that are critically needed?

Collaborative platforms are a strategic resource for powering research and innovation in advanced materials and it is for this reason, the BNCT Working Party is exploring existing and newly formed collaborative platforms in this report. Section 2 argues that newly formed collaborative platforms differ across many aspects and traditionally fall into two platform types. Section 3 characterises design elements for value creation based on evidence from 12 case studies which are explored in terms of funding, access, and IP policies. Section 4 discusses the functions and roles of collaborative platforms, notably the alignment and powering of value chains, fostering of standards, catalysing of innovation ecosystems and the creation of education, skills and social capital. Three key trends are elucidated in section 
5 , convergence, the intersection of platforms with society as well as digitalisation and digital-focused platforms. Section 6 presents policy implications and conclusions for governments and platform actors. The Annex contains detailed case study information which is referred to throughout the report.

\section{Types of Collaborative Platforms}

Collaborative platforms for advanced materials involve different types of stakeholders, different mixes of public and private actors and may focus on catalysing activities at the pre-commercial or commercial market stage. They can act as a nexus between disciplines, creating hubs of interdisciplinary research and development. Such interdisciplinary nodes can be a resource, for example, where the convergence of expertise from different fields can benefit users of the platforms in their individual projects. Given the plethora of different platforms models, this section introduces platform types and illustrates with examples drawn from the twelve case studies, included in the Annex.

It will become evident in the report that most collaborative platforms for advanced materials consist of a mix of elements from different types. Nevertheless, it could be said that there are two broad types of collaborative platforms for advanced materials, each focusing on a different Technology Readiness Level: research intensive user facilities focus on rather low technology readiness (Type 1, see section 2.1.) and commercialisation focus clusters and networks focus on rather high technology readiness (Type 2, see section 2.2.). Hence, both types are to be understood as two extremes of a continuum and their purpose is to aid understanding and appreciating platform diversity.

\subsection{Platform Type 1: Research-intensive user facilities}

Platform Type 1, "Research-intensive user facilities", focus on Research and Development $(R \& D)$ and early technology readiness. Collaborative platforms of this type tend to centre on the co-location of scientific and technological supports for the development of advanced materials within the area. Their role tends to be to support users to undertake research and technology development.

In Type 1 platforms, R\&D activities tend to be tied to technical facilities, that is the instrumentation itself and the skills that are needed to operate them. These facilities require significant investment for the specialised space (clean rooms, vibration isolation, etc.) as well as for the cutting-edge tools and equipment that are often too expensive for individual colleges, universities, or companies to purchase on their own. User facilities have the potential to leverage resources to acquire, maintain, and upgrade this high-end equipment and support the technical expertise to make the most of them. User facilities include the physical tools for fabrication and characterisation, synchrotron light sources for x-ray studies of materials, and high-throughput supercomputing resources for advanced modelling and simulation. In addition, some advanced materials research involves the development, construction and implementation of new instruments.

Type 1 collaborative platforms are capital-intensive, providing capabilities that otherwise would not be available to research and innovation ecosystems. They can be one large physical facility with widespread access (including international), as it is the case of the Iberian International Nanotechnology Laboratory (INL, see Annex section 7), or are based on centres or geographical districts where specific, often complementary, instrumentation, infrastructure and a skilled technical workforce are locally agglomerated (Robinson, Rip and Mangematin, 2007 $[3]$ ). As in the case of the NNCI (see Box 1) and the Nanotechnology 
Platform Japan (see Annex section 6), individual centres may be networked to provide national infrastructures with a centralised user gateway, guiding potential users to appropriate facilities.

\section{Box 1. Example of a Type 1 platform - the National Nanotechnology Coordinated Infrastructure (NNCI)}

The NNCI is a network of user facilities funded by the National Science Foundation (NSF), the case study on can be found in the Annex in section 12. The goal of the NNCI network is (1) to provide open access to state-of-the-art nano-fabrication and characterisation facilities, their tools and staff expertise across the United States, and (2) to use network resources to support education and outreach, as well as societal and ethical implications programs in/of nanotechnology. The network provides access to fabrication and characterisation facilities for researchers from universities, industry and government. Specific procedures and policies vary between sites, but a network-wide web-based interface collects basic information regarding tool or technique required and geographic preference. A representative from one of the relevant sites will follow up on the request to gather more information regarding the specific need and discuss terms regarding timing, fees required, training, and other details. The NNCI network staff often collaborate to identify the best options based on the nature of the request.

The NNCI as a platform is funded by the US Federal government and the individual sites augment that support with user fees and contributions from other sources. The NNCI sites are located in 17 states across the country and involve a total of 29 university and partner organisations, providing access to leading-edge fabrication and characterisation tools, instrumentation, as well as scientific expertise that spans a wide variety of disciplines related to nanoscale science, engineering, and technology. Facility users come from a broad range of technical areas and stages along the technology development spectrum, from early stage academic researchers to industrial developers. For example, in year 3 , the private sector accounted for $14.3 \%$ of NNCI network users (1,870 users) and $14 \%$ of user hours. This mix of technical expertise and perspectives creates a vibrant ecosystem for collaboration that benefits the overall research and development efforts.

\subsection{Platform Type 2: Commercialisation-focused clusters and networks}

The second collaborative platform type centres on the transformation of a technology into a product on the market, thus rather advanced technology readiness. Consequently, Type 2 focuses on connecting relevant stakeholders to translate a novel material (or family of materials) into application. Collaborative platforms of this nature are labelled as "Type 2: Commercialisation-focused clusters, consortia and networks", since the focus is on the commercialisation market stage and often integrates a variety of stakeholders from the materials value chain. Type 2 platforms can be a combination of public and private sector actors and may focus on different elements of the innovation chain, contrary to Type 1, which is capital intensive and requires large investments in infrastructure and technical staff. 
Type 2 collaborative platforms place an emphasis on the development and commercialisation of advanced material enabled products. Thus, great effort is focused on connecting the supply side of advanced material development with the demand side of technology markets. They may for example focus on scaling up already demonstrated process technologies or developing technical standards to catalyse market formation. The range of technology readiness of Type 2 platforms cover varies; they can be tightly focused or stretch widely across the spectrum. One example of the latter is innovation test bed for lightweight embedded electronics (LEE BED) focusing on accelerating potential supply side material option into various markets that would benefit from light-weight embedded electronics. Another example is the Austrian Smart Systems Integration Research Centre (ASSIC) (see Box 2). Since advanced materials are often a component of a technology product or device, it is not uncommon that Type 2 platforms have a large network of private sector partners stretching from highly specialised technology firms to large consumer market focused firms.

\section{Box 2. Example of a Type 2 platform - the Austrian Smart Systems Integration Research Centre (ASSIC)}

The ASSIC aims at stimulating new research ideas, encouraging technology transfer and strengthening innovative capacities of companies through promoting the establishment of platforms for joint research between industry and academic research. The broad objective is to initiate new product, service and process innovations.

ASSIC fosters cooperation between leading Austrian industrial actors and research institutes as well as international partners along the whole technological value chain. Currently, there are 15 industrial partners (e.g. Infineon, AVL LIST GmbH, Philips Austria $\mathrm{GmbH}$ ) as well as ten different academic research partners (e.g. University of Vienna, Johannes Kepler University Linz). The industrial partners range from SME to large industrial companies. Six of these partners are international players. The current COMET program in which ASSIC is participating has a duration of eight years with two funding periods, each lasting four years. The continuation of the COMET Centres within the second four-year-phase is conditional on a successful mid-term evaluation. COMET-Centres (here K1) are financed by $40 \%-55 \%$ public funding, at least $5 \%$ by scientific partners, and at least $40 \%$ by companies.

Overall ASSIC has currently 131 employees whereof 103 are scientists. ASSIC is operated by Silicon Austria Labs (SAL), a limited liability company where $50.1 \%$ is owned by the Republic of Austria, $10 \%$ by the Styrian Business Development GmbH, $10 \%$ by the Province of Carinthia, $4.95 \%$ by the Upper Austrian Research $\mathrm{GmbH}$ and $24.95 \%$ is owned by the Association for the Electrical and Electronics Industry.

Twelve case studies from six countries and the European Commission provide rich empirical material and show the diversity of collaborative platforms for advanced materials. Applying these ideal types to the twelve case studies resulted in the observation that most collaborative platforms for advanced materials consist of a mix of elements from different types. Moreover, it became clear that an emergent type of digital-focused 
platforms (Type 3 will be further discussed in conjunction with the key trend of digitalisation (see section 5) is prevalent in addition to the traditional platform Type 1 and Type 2 .

Figure 1 provides a general overview of the twelve case studies and shows this platform 'type mix' in an indicative manner. Three grey shades are used to show: Type 1 (researchintensive) in light grey, Type 2 (commercialisation-focused) in medium grey and Type 3 (digital-focused) in dark grey.

Figure 1. Case study overview and type mix

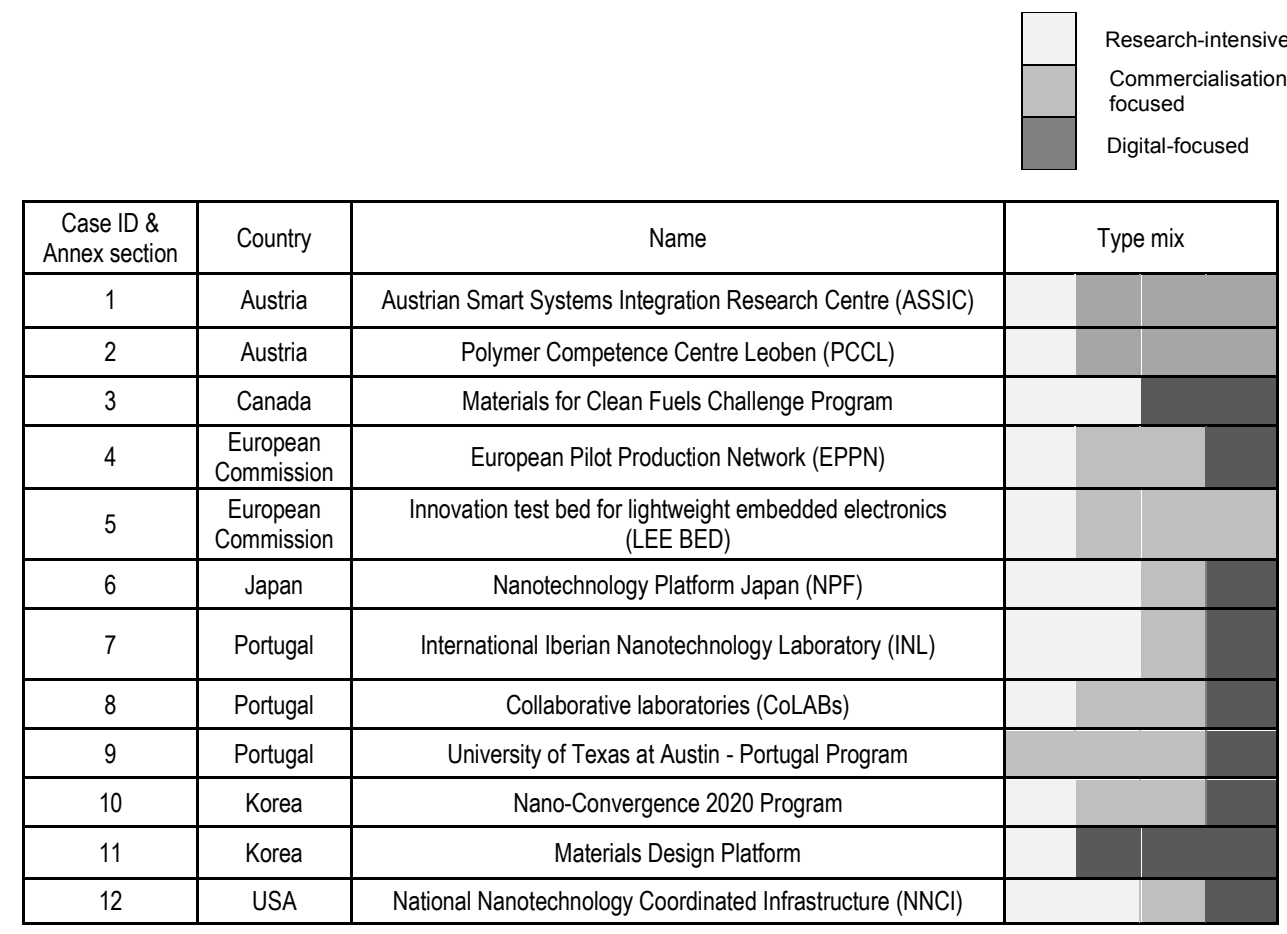

Source: developed by the project Steering Group.

\section{Design elements for value creation}

How can platforms create, support and sustain value? One way to address that question is through the notion of business models. A business model describes the design or architecture of the value creation, value delivery and value capture mechanisms employed by an organization (Teece, 2010 $[4]$ ). Value creation through business models involves a complex, interconnected set of exchange relationships and activities among multiple players, often as part of innovation ecosystems (Zott, Amit and Massa, 2011 ${ }_{[5]}$; Adner and Kapoor, $\left.2010_{[6]}\right)$. Value can be monetary or market value, but just as easily concerns intangibles, public goods, and services. 
The business models of collaborative platforms, as one might guess, vary as much as the structure, goals and objectives of platforms. For one thing, there is not one model of value for platforms. For Type 2 platforms that tend to focus at higher technology readiness with a strong view towards developing products, value creation mainly consists in the development of IP or the production of new products and perhaps firms. For Type 1, platform value creation is linked to creating and disseminating knowledge, jobs, workforce qualification, training or economic development which are also a form of intangible value.

In a more fine-grained analysis of the case studies, three interrelated elements of the business models of collaborative platforms take central importance: funding structures, access models, and IP. These elements represent policy choices and levers for building and sustaining different kinds of value.

\section{Funding}

Collaborative platforms for advanced materials require facilities, equipment and skilled technicians. These come at significant cost. Who should bear that cost? The financing of collaborative platforms can be public, private or a combination of sources. The mixture and feasibility of financing mechanisms tends to be dependent on the stage of technology development that the platform targets. Platforms targeting early technologies may find it difficult to capture financial resources from the eventual innovation stemming from the research they facilitate, since this will bear fruit further along the value chain, where different stakeholders are involved in upscaling and commercialising. Collaborative platforms that target rather advanced technologies focus on creating technologies for the market, therefore it is much easier to capitalize on investments e.g. by leveraging IP.

Type 1 platforms, since such facilities are expensive and take some time to construct, require significant investment (both financially and in training of the workforce) over a period of time. Focusing on infrastructure to provide state-of-the-art research facilities and skilled staff, is more capital intensive and requires significant continued financial backing in order to remain relevant as technologies mature and needs change. Constant strategic monitoring mechanisms can be used to ensure that the platform infrastructure evolves to meet changing user requirements and avoid sunk investments.

In the aforementioned workshop held in Braga, some workshop participants argued that such facilities can only be financed by the public sector due to costs and the emphasis on early technology developments inhibiting upfront investment by firms. Other participants argued that some form of financial "payback" from the private sector benefiting from these platforms should be encouraged whether it be direct financing or in terms of other investments in the research and innovation ecosystem. In some cases, user fees may help to address this issue, as they can be adapted on a sliding scale depending on the source of funds and whether the outcomes are made public or kept proprietary.

The Nanotechnology Platform Japan (see Annex section 6) highlights how sustained investment in maintenance and upgrading of infrastructure and skilled technicians is both essential and a challenge. For example, when the NPF started, equipment was purchased or renewed by a dedicated special budget in the first year. Eight years later, with ageing equipment, renewing the platforms infrastructure is a major issue. Therefore, the intended duration of the platform is important to ensure the platform meets its goal. This is among the challenges that funders, managers and operators of research infrastructures face all along the various phases of the platform's life-cycle (OECD, 2017 $[7])$. 
Platform sustainability, defined as "the capacity of a collaborative platform to remain operative, effective and competitive over its expected lifetime", is directly associated with platform financing in the medium and long term. This aspect is dependent on the intended duration of the platform: typically, a program might have a relatively short, well-defined duration, but a platform based on infrastructure is typically set up to operate in the medium or long term. In the latter case, policies must be in place to ensure that funding, perhaps evolving in nature over time (public fixed/competitive, private in different forms), is in place for the intended duration of the platform and is reflected in its business model. The difficulty and importance of attracting financing from different sources manifests in different ways for Type 1 and Type 2 .

Public funds are generally used for activities with low technology readiness, i.e. in precompetitive situations and motivated by national policies. Public financing of platforms with focus on mid to high technology readiness become problematic in some national contexts where there may be a policy to not distort competition. A counter example to this is the European Commission Framework Programme, which is supporting a network of European pilot plants, concentrating on demonstration and upscaling (see Annex section 4) with a focus on SME access. In this example, individual piloting activities are benefiting from public financing, highlighting that in a transnational setting, research and innovation funding operates under different legal frameworks

\section{Access}

Policies governing access to platform data and infrastructure are one of the primary policy levers for governing a collective resource like a collaborative platform and for designing a business model. The way access to a collaborative platform is handled varies across the platforms and can be divided into two models: (1) membership and (2) open access models.

An examples of the first platform access model based on membership are the two Austrian cases (in Annex section 1 and 2). Companies of any legal form and institutions of research and knowledge dissemination are eligible to participate in these collaborative platforms of so-called COMET (Competence Centers for Excellent Technologies) Centres. Participation in the platform is possible after becoming a partner of the COMET Centres which is possible during the application phase for a new COMET Centre or for the continuation of an existing one. In this application phase, the consortium leader describes the planned project with its associated costs as well as the participating partners for the upcoming funding period. Partners of the platform may participate in the platform via single-actor, multi-firm or strategic projects. The participation is evidenced by a "Letter of Commitment" including the relevant contribution (cash/in-kind) and rights and obligations of the partners are specified in an agreement.

The second platform access model is based on open access, where potential users of platform resources and infrastructure are subject to an evaluation. An example of this is the Innovation test bed for lightweight embedded electronics, which is funded through the European Commission Open Innovation Test Bed initiative (see Annex section 5) This initiative also espouses "open access" which means in this context that any interested user, from Europe and beyond, can access the test beds' facilities, capabilities and services independently of whether this user is part of an Open Innovation Test Beds consortium. Access must be granted at fair conditions and pricing and with transparent and mutual obligations with regards to, for instance, security, safety and intellectual property rights. 
Furthermore, in the US case study of NNCI (see Annex section 12), a network of facilities to enable research and innovation nationwide, access is determined on a case by case basis with regards to the specific need, the timing, fees required, training, etc.

The Japanese example (see Annex section 6) is an example of what might be called a 'usedetermined' access policy. The platform offers five services: (1) usage consultation, (2) technical consultation, (3) use of equipment through user operation, (4) commissioned research requesting operation by platform engineers, (5) collaborative research between a user and the platform. For the Japanese access model, fees such as the price of the equipment usage and technical staff's support, differs depending on whether the research activity is publicly available or not, with the cost being higher if it is not open. If a user chooses to be open, they will be obliged to create a report and make it publicly available.

A cross-analysis of the twelve case studies reveals that there are some challenges with regards to access. For example, the Austrian cases point out the fact that fees can be a barrier for participation of some stakeholders, especially for SMEs or academic units. From SMEs to larger firms, participants must see value in using the platform and mechanisms must be found to enable participation. The special challenges for SMEs was echoed in the Japanese case, opening up the question of whether SME-specific access should be developed to encourage use of Type 1 platforms and participation in Type 2 platforms. Another challenge for Type 1 platforms is the geographical location of the facilities may also be a barrier to participation, since using the facilities usually involves accommodation and living costs. Some sites have solved this problem by incorporating short-term accommodation facilities within the premises, such as in the International Iberian Nanotechnology Laboratory (see Annex section 7).

\section{Ownership and intellectual property}

Intellectual property (IP) is one source of value within collaborative platforms, and is a core aspect for the implementation and running of a collaborative platform. It has an influence on the collaboration potential of a platform because of the need to balance the potential for discoveries (exploration) and commercialisation (exploitation). Compensation may not solely be monetary, for example, licensing is related to revenue generation and the control of the invention, with the latter being a non-monetary benefit (OECD, 2013 ${ }_{[8]}$ ).

The analysis of the twelve examples provided in the Annex, reveals a striking similarity in IP policy. This can be summarised as "what I create is mine, what you create is yours and what we create together is ours'. The implementation of this policy, in terms of IP ownership and access fees, differs across the platforms.

The form and ownership of IP, stemming from activities conducted in the collaborative platforms, differ depending on the nature of the collaboration of the platform. Using the same examples described above for access, in the Austrian cases (both Type 2 platforms), unless otherwise stated, IP belongs to the platform. This may differ slightly for other Type 2 platforms that act as value-chain incubators. The IP rights and licensing arrangements of the European Pilot Plant Network (EPPN, see Annex section 4), for example are made on an individual basis between the members of the platform who decide to work together. In contrast, the technology of the digital platform that is central to the EPPN (i.e. the connecting tool) belongs to the EPPN consortium and EPPN owns the data gathered from the use of the digital EPPN platform. 


\section{Box 3. Example of active IP leveraging by a platform - the Korean Nano-convergence platform}

The Korean Nano-convergence platform (see Annex section 10), places a large emphasis on leveraging existing publicly owned IP. The goal of this platform is to achieve new product commercialisation or a manufacturing process innovation by linking patented nanotechnologies held by the public sector (university or research institute) and companies with commercialisation ideas in the field of nano convergence technology. The platform provides support for up to 3 years to link outstanding nanotechnologies (patented), which can be commercialised, held by the public sector with the real demand of the industry for achieving fast commercialisation (commercial product).

One success story of this initiative is the development of the world's smallest and most sensitive thin film fingerprint recognition module by CrucialTec - the manufacturer of Optical Track Pad mobile input devices - applying a novel patented design of transparent conductive electrode combined with its own IC drive. The technology of this ultra-thin BTP(Biometric Track Pad) fingerprint recognition module has improved processing speed of fingerprint authentication by $30 \%$ compared to previous system and has been sold to various global smartphone companies.

For the NNCI (a Type 1 platform, see Annex section 12), there is no network-wide IP policy and NNCI sites adopt IP policies of their parent university. The ownership of specific IP may depend on several factors governed by the host university policy including where work was performed and if done by staff or by the external user, whether staff contributed significantly to the development of the IP, and whether the user is an academic or industry partner. For the Japanese example (also a Type 1, see Annex section 6), IP issues are dependent on which of the five services are being mobilised. For example, a patent created from activities in service (2), (3) and (4) is owned by the user, and a patent born in (5) is shared by the user and the platform. In some cases, platforms can be created to actively leverage publicly owned IP. The example of the Korean Nano-convergence platform is an example of such an initiative, which has contributed to a number of commercial products (see Box 3).

\section{Functions and roles of collaborative platforms}

Advanced materials platforms power collaboration thereby driving emerging value chains and industries. In this regard, three key functions were particularly striking during the analysis of the twelve cases: (1) aligning and powering value chains for new advanced material options, (2) orchestrating the development of technical and data standards and (3) engaging with local innovation ecosystems. These three underscore the different kinds of value collaborative platforms can bring to the challenge of enabling emerging technologies.

\section{Align and power value chains}

Collaborative platforms, particularly those of Type 2, act as a nexus of market -oriented stakeholders (demand side) and technology producers (supply-side). They can align and help produce new value chains for new advanced material options thereby functioning as support systems for the technology readiness journey of a novel material. One example of this is the innovation test bed for lightweight embedded electronics (see Annex section 5), which focuses on coordinating the upscaling of novel nanomaterials for embedded 
electronics and transforming them into their products and production lines. To do this, the platform divides activities into three stages (see Figure 2). The first step is that a potential novel material receives a techno/economic and safety assessment from the platform to test its viability. If the assessment is positive, stakeholders have the opportunity to perform a pilot project in the next phase. Phase II is supported by a consortium of well-established large research and technology organisations (RTOs). Examples include the Fraunhofer Institute in Germany, and TNO from the Netherlands. These RTOs provide infrastructure to make pilot projects based on phase I modeling and assessments.

Figure 2. The three-phase process of LEE BED

Type the subtitle here. If you do not need a subtitle, please delete this line.

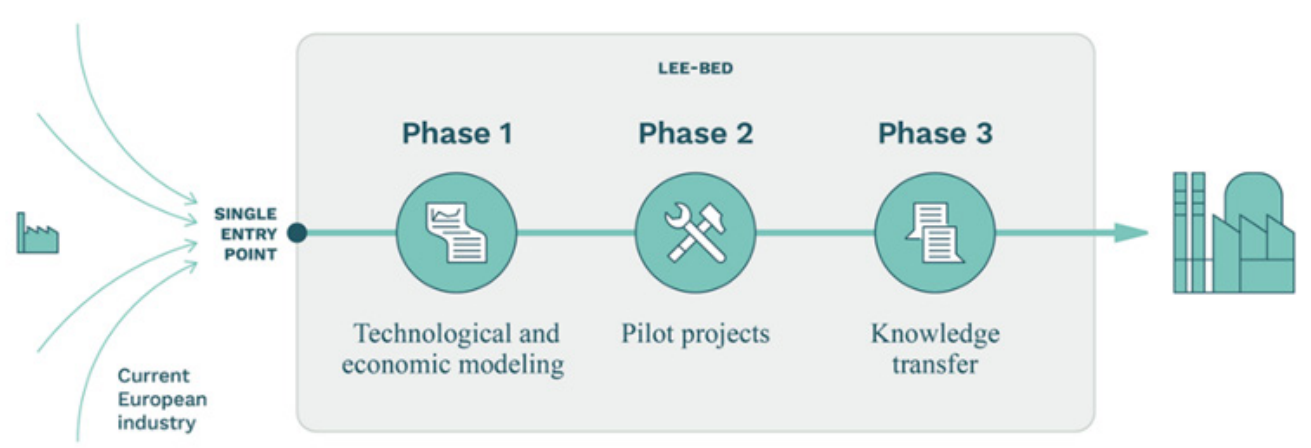

Source: Provided by the case study authors.

Successful pilot projects go through phase III and receive a final knowledge transfer, consisting of IPR discussions and final business plan check. This is supported by user firms in light-weight embedded electronics such as construction firms (Acciona Construccion), Luxury goods (Swarowski) and energy harvesting companies (Kinetron). In this way, the platform coordinates different sections of the value chain and catalyses the transformation of novel advanced materials from demonstrator into product.

\section{Foster standards}

Collaborative platforms can shape markets by fostering standards, regulation and good practices. Technical standards, for example, can be considered a form of market infrastructures since they are necessary for quality control, interoperability and to support regulation. Collaborative platforms for advanced materials development (both Type 1 and 2) play a key role in the development and testing of standards in their various forms.

Data standardisation was important for many of the analysed platforms: it allows for interoperability, however, inconsistent data formats across research organisations and universities both within countries and internationally hinder data sharing which was particularly highlighted. The lack of long-term funding commitments emerged from the discussions at the Braga workshop and from the case study analysis as an explanation for the reluctance to set standards on data formatting across universities. Another issue on this is data quality and the management of data curation processes which is labour intensive and costly. Data standardisation may be led by the private sector, as it was in the early days 
of additive manufacturing (3D printing technology), where the company 3D Systems developed STL (STereoLithography), a generic 3D file format suited for additive manufacturing, which was made freely available (Robinson, Lagnau and Boon, 2019 ${ }_{[9]}$ ). STL quickly became a de facto standard among professional additive manufacturing users and drove the growth and maturation of additive manufacturing technology and services.

With regard to advanced materials, key challenges for data sharing include expertise, cost, and the lack of incentives for companies to do so. Governments could play a vital role by linking public funding with data sharing (see for example the case of Japan in Annex section 6) and proper data curation processes. The latter is important, for example in the form of specific work plans what kind of data will be correlated, as not only data collection, but its curation based on clear application targets is important when managing research data coming from diverse fields.

Government could encourage the use of certain standards to enhance compatibility. A note of caution was raised on the risk that even if funding agencies force the sharing of data, there is no guarantee of the quality of data.

\section{Catalyse innovation ecosystems}

Collaborative platforms not only align and power value-chain formation and foster standards, as discussed previously, but also drive and coordinate systems of stakeholders that may be beyond individual projects and contractual relationships with the specific platform. The notion of an "innovation ecosystem" has been used to show that platforms coordinate a wide range of actors that operate in the same field, follow the same rules and play specific discrete roles in the ecosystem without formal contractual agreements or alliances (Jacobides, Cennamo and Gawer, 2018 ${ }_{[10]}$ ). Paraphrasing, Prof. Ferrao who observed during the Braga workshop that the "glue" that binds actors together in innovation ecosystems is (a) a shared notion of value, (b) complementarity of ecosystem members and (c) mutualistic relationships.

The innovation ecosystems perspective argues that there is an ecology of actors linked through symbiotic, mutualistic (or even predator/prey) relationships (Jacobides, Cennamo and Gawer, 2018 $\left.8_{[10]}\right)$. This pertains to collaborative platforms for advanced materials in two ways: on the one hand, they aim to seed and catalyse ecosystems that they are part of; on the other hand, they themselves can have ecosystem-like properties, such as elements which are mutually enhancing and that operate in concerted way. In other words, the ecosystem concept helps to understand what platforms are and how they operate, but also what environment they are trying to create around them.

The analysis of the case studies revealed that a collaborative platform for advanced materials can touch many ecosystems or can be the basis of an ecosystem. For example, the NNCI sites (see Annex section 12) serve as epicentres to collaborative ecosystems in their regions. Bringing together faculty, students, researchers, industry, and the business development community from a wide variety of disciplines creates an atmosphere of collaboration where these areas converge. The cutting-edge tools and expertise to fabricate and characterise materials and devices pushes the boundaries of technology areas as diverse as electronics to medicine.

The Canadian example of the Materials for Clean Fuels Challenge Program (see Annex section 3), is explicitly designed as an ecosystem builder. With the aim of providing an integrating and coordinating role, supporting funding and networks, to harmonise these efforts towards well-defined and focused greenhouse gas (GHG) emissions reduction 
objectives and to catalyse setting rules and standards in this emerging domain. This case stands out among the cases analysed in that it does not only aim to catalyse an innovation ecosystem, but to drive it towards a specific mission.

\section{Build education, skills and social capital}

Another key strength and potential for collaborative platforms is to build skills and develop human capital. An example where this form of value creation is the central objective are Collaborative Laboratories (CoLABs) in Portugal (see Annex section 8), which are nonprofit private associations or companies. Their main goal is to create skilled and scientific jobs in Portugal, both directly and indirectly, by implementing research and innovation agendas geared at creating economic and social value.

Also in the case study from the United States (see Annex section 12), education and workforce development are a critical component of the NNCI with the mission of these efforts to "offer education and training to address the growing need for a skilled workforce and informed public; provide resources, programs, and materials to enhance knowledge of nanotechnology and its application to real-world issues; and support the US economy by enabling a STEM-literate workforce ready to meet the technological challenges of a nanoenabled economy as well as an informed citizenry that supports continued and safe growth of nanotechnologies". ${ }^{1}$

In Japan, the Nanotechnology Platform (see Annex section 6) has its own programme of schooling and training for students and technical staff using NPF facilities, and exchanging information and networking activities for young researchers. NPF operates an award system in the form of technical level certificates for technical staff in order to provide motivation of their up-skilling and career path development.

In addition to these examples of human capital development, collaborative platforms for advanced materials also foster the creation of interpersonal relationship which manifests in a shared sense of identity, norms and values for actors who become involved in joined projects at the respective platform. This intangible, relational value may even extend beyond the scope of the respective technology platforms. At both examples of collaborative platforms in Austria (ASSIC and PCCL), long-term networks and partnerships are established, in which each partner gets to know the fields of activity of all other partners involved. This may also result in cooperation between certain partners outside the platforms. In fact, long-term partnerships have led to joint developments and projects outside between partners of ASSIC as well as between partners of PCCL. The implementation of joint projects outside the platforms is facilitated by the common basis of trust and knowledge of respective scientific and industrial communities.

\section{Key Trends}

Three key trends emerged in the analysis of the case studies that have been shaping the nature, impact and policy support of collaborative platforms for advanced materials. The first key trend is convergence, a concept that refers to the platform serving as the point where various aspects of the research and development community come together and converge. The second trend is on the increasing importance of platforms and their intersections with wider society. The third trend is that digitalisation affects many analysed collaborative platforms for advanced material in some way. 


\section{Trend 1: Convergence}

Convergence refers to the melding of disciplines and actors where research challenges can give rise to, and are pursued within, a common framework and language. It is closely akin to "transdisciplinary research" (OECD, 2020 $[11])$, but puts significant attention to fields of emerging technology. Technology convergence refers to specific instances of convergence at the level of research and innovation activities. It is more than just a combination of different disciplines or technologies. Ideally, convergence adds significant value, and results in completely new ideas, methods and outputs. In short, "Convergence occurs where scientific disciplines or key enabling technologies combine with other disciplines or enabling technologies and promise new or added value beyond synergies" (OECD, 2013, p. $\left.9_{[12]}\right)$. In the context of collaborative platforms for advanced materials, this broad description can be further elaborated into three sub-categories:

1. Diverse disciplines: collaborative platforms can be vehicles to bring together previously separate disciplines of science and technology. The NSF refers to this as 'deep integration across disciplines' in terms of knowledge, theories, methods, data, research communities and languages become increasingly intermingled. ${ }^{2}$

2. Diverse technologies: the discussion of collaborative platform types (in section 2) highlighted the important function bringing together technologies and their stakeholders from development stages and different technology categories (e.g., nanotechnology and digital technologies/AI). Research-intensive user facilities (Type 1) focus on rather early technology readiness and commercialisation-focused clusters and networks (Type 2) with an emphasis on rather advanced technology readiness.

3. Diverse actors: collaborative platforms can enable interactions and exchanges between communities of individuals with various backgrounds. The degree of inclusivity of different actors can vary between platforms - either solely focused on actors with research expertise to also integrate engineering or industry perspective and others which also include or cater for societal actors.

Figure 3 provides a schematic representation of how diverse perspectives, disciplines, approaches and actors can give rise to new sciences, knowledge, and innovation.

Figure 3. Schematic overview of convergence in advanced materials collaborative platforms

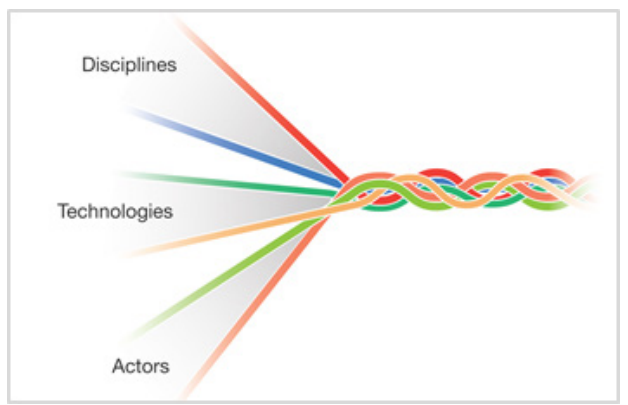

Source: Illustration credits: Sylvain Fraccola

In the early days of nanotechnology, cutting-edge work was at the boundaries of traditional disciplines such as materials science, engineering, biology, chemistry, and physics. While these disciplines still exist, nanotechnology has grown out of a convergence of these and other disciplines with a common language and a strong nanoscience community. As 
nanotechnology continues to mature, this community is increasingly converging with other areas such as neuroscience and information technologies. This convergence of disciplines creates synergies that result in outcomes that are "greater than the sum of its parts". The increasingly complex global problems, such as sustainability, climate change, equality and pandemic response, require solutions that transcend traditional science and technology disciplines.

The advanced materials collaborative case studies demonstrate that the platforms facilitate convergence among disciplines. For example, by bringing together researchers from different disciplines around shared use of tools. The user facilities classified as type 1 seed this convergence which can start with specific interdisciplinary collaborative projects, or be the focus of the site such as at INL (see Annex section 7) or the National Center for Earth and Environmental Nanotechnology Infrastructure $\left(\right.$ Nano Earth $\left.{ }^{3}\right)$ in the United States. Nano Earth is one of 16 nodes of NNCI (see Annex section 12) at which engineering and geosciences converge to study environmental challenges.

The analysis of the case studies also unveiled the convergence of actors with different perspectives and expertise areas. Concretely, the collaboration of researchers and developers at collaborative platforms accelerates innovation and commercialisation of technologies and builds trust between the different parties that can extend beyond the scope of the platform.

Both examples of collaborative platforms in Austria (ASSIC and PCCL, see Annex sections 1 and 2) foster interdisciplinary teams which cover the entire technological value chain. A wide range of actors are active in the same field in these COMET Centres. They are either from the academic sector, ranging from students to senior researchers and experienced research laboratories, or from the industrial sector, where both small innovative companies and large players are partners of the Centres. Overall, COMET Centres aim at stimulating new research ideas, encourage technology transfer and strengthen innovative capacities of companies, and should initiate new product, service and process innovations.

\section{Trend 2: Working with and for society}

The ability of the platforms to promote convergence highlights the potential to bring together diverse perspectives and backgrounds to raise awareness and address social issues. Convergence of varying and diverse socio-economic, gender, racial, and cultural backgrounds also breeds more robust solutions that help to ensure that a broad range of perspectives are taken into account. Inclusiveness is a key issue in this respect and the analysis illustrated that the platforms serve to converge researchers with societal actors in a variety of ways. This aspect leads to the discussion of the second trend on the intersection of collaborative platforms for advanced materials with society.

Thus, technological and societal aspects have become integrated to a greater degree than ever before in collaborative platforms for advanced materials. In fact, this relationship between technology, i.e. the collaborative platform, and the broader society is reciprocal. Some governments have recognised the importance of reflection on societal aspects of nanotechnology research and innovation (see example in Box 4). 


\section{Box 4. Examples from the United States - Integrating societal dimensions of technologies in platforms}

The US government has invested in research activities focused on the societal dimensions of technology. With respect to nanotechnology, this was done by incorporating language into the key federal funding instrument -the 21st Century Nanotechnology Research and Development Act (Public Law 108-153) - requiring funded research programs to:

Identify ethical, legal, environmental, and other appropriate societal concerns
related to nanotechnology, and ensur[e] that the results of such research are widely
disseminated' (s.2 (b) (10) (A)) and 'insofar as possible, integrat[e] research on
societal, ethical, and environmental concerns with nanotechnology research and
development, and ensur[e] that advances in nanotechnology bring about
improvements in quality of life for all Americans... $(s .2(b)(10)(C))$.

The US NNCI (see Annex section 12) has integrated the need to reflect on the potential impacts of nanotechnologies as they are discovered, developed and implemented. The Associate Director for Societal and Ethical Implication (SEI) of the Coordinating Office works across all of the NNCI sites and assists in the development of SEI research and engagement programs. The NNCI hosts major SEI training efforts every year including a policy workshop in Washington, DC and an event called the "Winter School on Responsible Innovation and Social Studies of Emerging Technologies." Individual nodes also have specific activities including NanoEarth at Virginia Tech. SEI activities initiated within NanoEarth include engagement with diverse and underrepresented groups, empowerment of individuals and social change through nanotechnology entrepreneurship, and earth and environmental nanoscience in the service of society.

The strengthening link between technology and society has resulted in an increasing focus on the intersection of collaborative platforms with societal actors. This has been manifesting in two ways. On the one hand, in societal engagement by means of contributions from different actors to platforms and, on the other hand, greater societal relevance of platforms when responding to societal needs and addressing societal challenges with so-called mission-oriented platforms.

\section{Engagement with societal actors}

The engagement of civil society takes various forms for the different platform types. For Type 1 platforms, where large facilities and infrastructures are involved, linking with society and reflecting on societal implications of research and innovation may be part of building trust within the local community and the innovation ecosystem.

For Type 2 platforms, where commercial products and applications are the overall aim, these aspects are essential for societal uptake of innovations enabled by advanced materials and vice versa, societal trends lead to new technological developments. For example, a trend towards smaller, faster, safer and more flexible products in the field of sensor technology led to the development of special functionalities at the ASSIC (see Annex section 1) which were desired by society. These drivers originate at the industrial as well as on the level of private households. In the future, personalised systems will play an even more important role in this field. 
An alternative example of how civil society engagement manifests in collaborative platforms for advanced materials is when the platform collaborates with outside actors from civil society in order to engage with the local community and make visible the activities and outcomes of the work in the platforms. The Scale Travels Initiative by the International Iberian Nanotechnology Laboratory (INL, see case in Annex section 7), launched by INL in 2015 with the aim to stimulate reflection and debate on societal, ethical, cultural and other impacts of nanotechnology, by mobilising the arts in various ways. This initiative includes artists in residence, where artists engage with the researchers at the centre, embed in the life of the laboratory and create artistic interpretations and explorations to stimulate the discussion on nanotechnology research and society. With art exhibit spaces in the city of Braga (where the INL is located) this provides a novel way of engaging with civil society through artistic exploration of nanotechnology (Moura et al., 2018 [13]). ${ }^{4}$

Collaborative platforms are tools for developing and improving scientific culture in society and educating the public about respective technologies and their potential application in day-to-day life. Hence, they play an important role in society which is another aspect of societal engagement of collaborative platforms. For example the NNCI (see Annex section 12) engages with the public through seminars and symposia, a radio series, community events, a traveling museum exhibit, as well as educational programs including classroom visits, teacher workshops and the dissemination of teaching resources.

\section{Responding to the greatest societal needs}

In addition to engagement with societal actors, they respond to societal needs by addressing societal challenges with so-called mission-oriented platforms tailored to local context. For example, integral part of the mission of the INL in Portugal (see Annex section 7) is to address societal challenges.

In the context of advanced materials, concrete societal challenges today are the pace in which rare natural resources are exploited as well as the issue of plastics disposal, particularly nano and micro plastics. These challenges have driven trends of the circular economy that require more life cycle assessments (LCA). These translate into so-called grand societal challenges which capture societal needs that are currently unmet and often require international and multisector solutions where disciplines, actors and technology development stages converge.

The nature of grand challenges is complex, due to various interdependencies making approaches to solving them difficult to articulate (Amanatidou et al. 2014). Missionoriented platforms tailored to local context follow the trend in research and innovation policy that aims to direct innovation captured by the notion of mission-oriented (vertical) policies (Foray, Mowery and Nelson, 2012 ${ }_{[14]}$; Mazzucato, 2018 ${ }_{[15]}$ ). Calls for a return to mission-oriented policies as a way to address grand societal challenges (Mazzucato, $2018_{[15]}$; Georghiou et al., 2018 ${ }_{[16]}$; Fisher et al., 2018 $8_{[17]}$ ) are spawning experimental kinds of collaborative platforms. Mission-oriented policies target the development of specific technologies in line with state-defined goals (missions); this differs from more horizontal policies aimed at institutional development in a systems of innovation approach (Cantner and Pyka, 2001 $[18]$ ). 


\section{Box 5. Examples from Canada - Collaborative platforms as tools to address societal challenges}

The Materials for Clean Fuels Challenge Program (see Annex section 3) is a collaborative research program focused on developing disruptive technologies to decarbonize Canada's economy. The Government of Canada has stated an ambition to become a zero-emission country by 2050 . Transformative technologies are required to reach this goal.

This collaborative program has three main thrusts $-\mathrm{CO}_{2}$ conversion, industrial hydrogen production, and artificial intelligence for materials discovery. Across these thrusts, the National Research Council of Canada (Canada's national lab system) collaborates with academics and SMEs in Canada and globally to achieve the program's goals.

Activities include advanced catalyst materials synthesis and discovery, device prototyping, techno-economic and life cycle assessment development for the nascent field of $\mathrm{CO}_{2}$ conversion, and the establishment and development of robotic AI-driven self-driving laboratories.

The Canadian case study (see Annex section 3), describes a recent initiative to address grand challenges for a specific national context. Projections ${ }^{5}$ suggest that by 2030 and without disruption in the form of an economically viable alternative technology that encourages early adoption, The Canadian federal government has made clean energy and low-carbon technologies a high priority. ${ }^{6}$ The replacement of coal- and gas-fired power grids with renewables based power grids provide easy emission reductions but introduce intermittency and seasonality problems. Its cold climate and sparse population makes Canada's hydroelectricity resources impractical harness. Canada's GHG emissions are dominated by the oil and gas, emissions-intensive chemical processing industries, and transportation sectors.

All these sectors presently rely on fossil fuels. While global energy sector developments focus on electrification and biofuels, and to a lesser extent on the use of excess renewable energy capacity to produce hydrogen via electrolysis, the implementation pathways for these technologies do not fully address Canada's unique needs and a gap remains. Specifically, there is a gap in technologies to address GHG reductions in the petrochemical, oil, and gas sectors. These sectors rely on the transformation of fossil fuels into feedstock chemicals and fuels. These transformations are typically carbon emissions intensive, requiring high heat and energy, and are therefore unsustainable.

This challenge for Canada has been translated into a mission-oriented program focused on basic research up to prototype stage. The Materials for Clean Fuels Challenge Program (see Annex section 3) is a 7-year $\$ 57 \mathrm{M}$ collaborative research program aimed to develop technology to decarbonize Canada's oil \& gas and petrochemical sectors. It brings together Canada's national labs at the National Research Council (NRC) with academic and smallmedium enterprise (SME) partners. The program seeks to develop high-risk, high-reward technologies at a rather low technology readiness towards prototype and demonstration. There is a strong emphasis on catalyst and membranes materials (and associated devices) for artificial photosynthesis and renewable fuels/chemical feedstock production. 


\section{Trend 3: Digitalisation and digital-focused platforms}

Digitalisation is a broad sociotechnical trend that promises to impact collaborative platforms in many ways. Today, global scale management of materials data is one of the primary issues in modern materials science. Infrastructure for data accumulation, the design of the scalable data repositories and a solid data curation strategy is paramount for virtual materials designs.

Looking at the Korean Materials Design Platform example (case 11 in the Annex), since 2017, the Ministry of Science, Technology and ICT of Korea has been developing policy measures to enhance access to research data generated and accumulated in the university, national research institutes and national R\&D facilities. "Strategy to Promote Sharing and Use of Research Data for Innovative Growth" was proposed for a systematic approach with multiple policy measures in 2018. The Korean strategy recommends establishing research data centres in each small field of research by granting diverse structures and attributes of material research data. At the same time, the Strategy calls for continuous efforts to curate and standardise research data across different fields of research, and eventually improve accessibility and usability of the data. ${ }^{7}$ This initiative is expected to largely influence the way in which research data are produced, managed and shared among researchers in Korea.

Artificial Intelligence (AI) is also integral to the digitalisation trend, and reshapes collaborative platforms for advanced materials. AI promises to be a crucial enabler for a more efficient use of data. The ability to deal with large amounts of data, rapidly and in an unprecedented manner will open new possibilities. This is envisioned as one of the key thrusts in the Canadian Materials for Clean Fuels Challenge Programm (see Annex section 3). AI-Accelerated Materials Discovery is the application of AI and digital technologies towards accelerating the pace of discovery. It is expected that materials development and R\&D in general will be heavily augmented by AI tools at the National Research Council of Canada going forward. Another example is the Materials research by Information Integration Initiatives $\left(\mathrm{MI}^{2} \mathrm{I}\right)$ at the National Institute for Materials Science of Japan. Recognising the increasing demands for material innovation due to continuous requirement for better performance and lower cost, conventional methods of material search is limiting. "Materials Informatics" as high-throughput materials development method based on data science is the driver of the $\mathrm{MI}^{2} \mathrm{I}$ platform combining data mining, machine learning and artificial Intelligence. ${ }^{8}$ Therefore, AI-supported materials design and development is a new and important stream of work in collaborative platforms for advanced materials.

Taking together the aforementioned notions of digitalisation in these collaborative platforms, an emergent platform type with its own particular contribution to advanced materials research and innovation emerges. It could be labelled as "Type 3: Digital-focused platforms" and both mobilises digital data on materials and may also include AI to support material design and development. These platforms are virtual in nature, but none-the-less have a range of infrastructural requirements which currently pose a challenge to harnessing the potential of the digital transformation of material research and development.

Evidence of digitalisation potentially revolutionising advanced material design and development is visible in the Korean Material Design Platform (see Annex section 11 and Box 6). Owing to the rapid increase in computing power and the development of efficient computation methods, (sub) atomic level simulation is initiating the new paradigm of materials research. Increased predicting power of ab initio calculations combined with molecular dynamics approaches can now guide experimental research and it is expected that the efficiency of materials (process) development can be greatly enhanced by using computer simulation or computing based pre-screening of potential materials. However, 
the entrance barrier for the advanced computational research is still high, due to theoretical and numerical complexities and elaborated high performance computing environments.

\section{Box 6. Example of a Type 3 platform - the Korean Material Design Platform}

Since 2009, researchers in the Korea Institute of Science and Technology (KIST) and their collaborators have been developing thematic platforms for materials design via multiscale simulation (from nano to macro scale). In contrast to conventional platforms, these "virtual laboratories" are dedicated to specific themes, for example the "virtual lab for nano-device optimization" or "virtual lab for the design of secondary battery materials" ${ }^{10}$, and "virtual lab for nano particle design". ${ }^{11}$

Virtual Fab for Nano Materials Design provides a simulation environment for nano materials where users can synthesise and manipulate nanomaterials to characterise their performance. The battery materials design platform (battery.vfab.org) provides various simulation environment relevant to the battery materials design, ranging from anode, cathode, electrolyte and solid-electrolyte-interface (SEI) design. In the catalyst design platform (qcat.vfab.org), multiscale simulation environment is established to generate and characterize the nano particle catalysts. In these web-based virtual laboratories, users can obtain the advanced multi-scale simulation results following the workflow very similar to that of rea-world experiments. Users prepare samples, conduct experiments virtually and then analyze the virtual sample in the same way as they usually do in the real laboratories.

Digitalisation promises to continue to shape collaborative platforms for design and development of novel advanced materials. The production and management of various digital data brings up issues of security and privacy. On the former, collaborative platform owners need to ensure data integrity and that no unauthorized access to the data is possible. Regarding privacy, some of the data may be private, for one reason or another, and only authorised users should be able to access them. Digitalisation also influences the way collaborative platforms are managed. Interoperability of data from different platforms is essential to maximise innovative potential of such digital platforms for advanced materials. For example, standards for data and processes are required, but also the data itself needs to collected, curated and stored in compatible ways by the different parties. It could also require compatible methods for data processing (e.g. modelling). Thus, there are clear standardisation and organisational issues that must be addressed if digital platforms for advanced materials are to reach their full potential.

\section{Policy implications and conclusions}

\subsection{Policy implications for platform actors}

The activities of different kinds of actors shape the design and implementation of collaborative platforms for advanced materials. On the one hand, institutional actors - such as research agencies, companies, government entities and research or higher education institutions - establish the overall framework conditions. On the other hand, individuals like subject matter experts from researcher or technical fields as well as other sectors in society - manage or work together in these platforms. 
The insights and findings from this report carry important implications for institutional and individual platform actors which are grouped thematically:

\section{Access, funding and standards}

Funding structures, access models, and intellectual property present key instruments for building and sustaining different kinds of value in collaborative platforms.

In order to create appropriate business models, platform developers should set out the life cycle ex ante - i.e. whether the platform's life is imagined to be finite or whether it is imagined as a longer-term resource.

The suitability of a platform access model - either by membership or open access - depends on the platforms business model and the ideal modalities of engagement. An open-access model with e.g. a fee-for-usage provides users with flexibility and can be a means to make datasets and algorithms readily available for the community to use and further develop. However, depending on the platform type and the nature of its infrastructure, this might not always be the best solution.

Fee structures for platform access should take into account the special needs of SMEs to encourage use of Type 1 platforms and participation in Type 2 platforms.

Governments and funders should encourage the use and development of standards, for example by having the use of standard data formats be a selection factor in awards. While this would contribute to ensuring data compatibility and improve the conditions for data sharing, it necessitates quality assurance and clarification of data property in platforms.

\section{Value creation and innovation ecosystems}

Collaborative platforms can be powerful vehicles for generating intangible value, including the creation and dissemination of knowledge. They can build human capital, e.g. by developing workforce qualification, training researchers at different career stages, creating jobs, and providing fora for public engagement and learning.

Platform actors should build on the intangible and relational value created from exchanges, joint activities and complementarity with others. This may extend beyond the scope of the respective technology platform and result in cooperation between partners outside the platforms.

Platform developers who set out to achieve a specific mission with the respective platform could explicitly design it to act as ecosystem builder, so that it integrates and coordinates platform activities in pursuit of its overall aim.

IP policies and workforce provisions in collaborative platforms can be used to help seed local innovation ecosystems, create value chains and develop human capital by building skills in workforce development programs and training researchers at different career stages, as well the wider public by education on nanotechnology and its application to realworld issues.

\section{Convergence and digitalisation}

The development of nanotechnology itself has grown out of a convergence of different disciplines resulting in a common language. Governments could use collaborative platforms to exploit convergence and to continue to drive a process of convergence, making 
them nodes where new or added value is created by combining scientific disciplines, enabling technologies and a diversity of actors.

Technology platforms can be a means to realise the potential of digitalisation in the field of advanced materials by:

- promoting access to data which improves platform attractiveness but which requires expertise, investments and incentives and standard setting

- transforming data provided by researchers into a standardised data format when building high quality databases

- fostering standard setting for data sharing by providing long-term funding commitments and support labour-intensive and costly data quality assurance and data curation processes

- creating incentives for individual researchers and companies to share data to such platforms via funding mechanisms

- co-building data analysis tools using data science and informatics methods to find the relationship of materials structure and property/function, and to find optimum materials

\section{Intersection with society}

Governments could develop collaborative platforms as physical or virtual spaces where technical communities come together with the broader society for mutual exchange and learning.

Collaborative platforms could serve as good vehicles for mission-driven policies as they are well positioned to orchestrate and coordinate diverse kinds of actors, technologies and disciplines, and channel them towards critical needs and goals.

Platform founders and funders should consider creating mechanisms for societal engagement. To this end, they should develop intramural and extramural programmes to communicate with the broader society, through e.g., putting humanists and/or artists in residence, offering tours of facilities to students and clubs, providing student internships, and engaging broader society in public spaces like science museums.

\section{Platform lifetime}

At platform creation, platform management needs to ensure a clear understanding of all partners and platform stakeholders by clarifying rules for collaboration up front and the life-cycle of the enterprise.

Throughout the existence of Type 2 platforms, commercialisation-focused collaborative platforms, the platform management needs to be attentive to pre-competitive forms of collaboration to bridge gaps in product development, etc.

\subsection{Conclusions}

The analysis of the case studies in this report has shown that collaborative platforms are important mechanisms for innovation in the area of advanced materials technologies. They can accelerate technology development by enabling the sharing of pre-competitive data and information as well as develop and de-risk capital-intensive early stage technologies, and also enable critical mass. Moreover, they remove redundancies and cost by sharing 
infrastructure and facilities and create a community around a technology which involves bringing together stakeholders with different perspectives and expertise areas from industry, research and society. This means that they can catalyse convergence and direct innovation ecosystems. The role of the platform may vary depending if they either are part of or seed a new ecosystems

The analysis of the 12 case studies showed that the resulting platform characteristics differ, depending on the platform type (see section 2). An important finding is that each analysed platform does not pertain solely to one type, but consists of a unique archetype mix. It became clear that the design elements of their business models, notably funding, access and IP, are important building blocks for pecuniary and non-pecuniary value creation (see section 3). Moreover, it is important to look at the value-add beyond traditional R\&I (Research and Innovation) indicators and to recognise the intangibles that these platforms are creating, as well as the need for funding plans which extend beyond seed funding.

The report detailed the functions and roles of collaborative platforms for advanced materials and highlighted their ability to align and power value chains, foster standards, catalyse innovation ecosystems and build human and social capital (see section 4). Key trends were discussed which have been shaping the operation and impact of collaborative platforms for advanced materials.

- Technology convergence has resulted in new ideas, methods and outputs of collaborative platforms for advanced materials. Concretely, convergence is a multidimensional concept that stands for the integration of research, industry and societal actors which bring differing expertise to the platform, the transformation of knowledge across technology development stages and the multiple science and technology disciplines required to successfully deliver platform projects.

- Intersections with society are gaining importance, which manifests in societal engagement, on the one hand, and mission-oriented platform programs, on the other hand. The former are reciprocal exchanges in the form of education and training, aimed not only at internal platform staff and next generation scientists, but also in terms of educating the wider public about platform activities and technology insights. Challenge-driven or mission-oriented research and innovation policies may become an important part of the global policy mix. In this context, collaborative platforms for advanced materials are an important vehicle to enable the "implementation" of missions. This is becoming a key issue for STI policy and for organisations wishing to apply mission-oriented approaches to address societal challenges such as creating a circular economy, addressing the lack of key resources and plastic disposal.

- Digitalisation of collaborative platforms for advanced materials has been an emerging trend, it has not only been cutting across traditional platform types, i.e. researchintensive user facilities and commercialisation-focused clusters and networks, but also resulted in the emergence of a third Type 'digital-focused platforms'. The change that digitalisation brings about for collaborative platforms is a double-edged sword: on the one hand, it can improve access to data, thus making platforms more attractive and inclusive because of the ability to reach new user groups. On the other hand, expertise, money, incentives and standard setting are required for data sharing to work which requires long-term funding, good data quality, data curation processes and clarity on data property in digital-focused collaborative platforms.

In the larger scale of things, collaborative platforms can be a means to democratise science by providing access to resources and enabling those in rural and remote areas -researchers, 
citizens, engineers, companies and universities - to access advanced technologies, infrastructure and data. This addresses the disparity between urban and rural areas and can become a driver in the revitalisation of the regional economy. 


\section{References}

Adner, R. and R. Kapoor (2010), "Value creation in innovation ecosystems: How the structure of technological interdependence affects firm performance in new technology generations", Strategic Management Journal, Vol. 31/3, http://dx.doi.org/10.1002/smj.821.

Anthony Brooks, E. (ed.) (2018), Creative Approaches on Interactive Visualization and Characterization at the Nanoscale, Springer, http://dx.doi.org/10.1007/978-3-030-06134-0.

Cantner, U. and A. Pyka (2001), "Classifying technology policy from an evolutionary perspective", Research Policy, Vol. 30/5, http://dx.doi.org/10.1016/S0048-7333(00)00104-9.

Fisher, R. et al. (2018), "Mission-Oriented Research and Innovation: Inventory and characterisation of initiatives", Report prepared for the European Commission by the JIIP, https://op.europa.eu/en/publication-detail/-/publication/3b46ce3f-5338-11e8-be1d01aa75ed71a1/language-en (accessed on 1 March 2018).

Foray, D., D. Mowery and R. Nelson (2012), "Public R\&D and social challenges: What lessons from mission R\&D programs?”, Research Policy, Vol. 41/10, pp. 1697-1702, http://dx.doi.org/10.1016/j.respol.2012.07.011.

Gawer, A. (2014), "Bridging differing perspectives on technological platforms: Toward an integrative framework", Research Policy, Vol. 43/7, pp. 1239-1249, http://dx.doi.org/10.1016/J.RESPOL.2014.03.006.

Georghiou, L. et al. (2018), Mission-Oriented Research and Innovation Policy: A RISE Perspective., http://dx.doi.org/doi:10.2777/426921.

Jacobides, M., C. Cennamo and A. Gawer (2018), "Towards a theory of ecosystems", Strategic Management Journal, Vol. 39/8, http://dx.doi.org/10.1002/smj.2904.

Katz, M. and C. Shapiro (1994), "Systems Competition and Network Effects", Journal of Economic Perspectives, Vol. 8/2, http://dx.doi.org/10.1257/jep.8.2.93.

Mazzucato, M. (2018), Mission-Oriented Research \& Innovation in the European Union: A problemsolving approach to fuel innovation-led growth, http://dx.doi.org/doi:10.2777/36546.

OECD (2020), “Addressing societal challenges using transdisciplinary research”, OECD Science, Technology and Industry Policy Papers, No. 88, OECD Publishing, Paris, https://dx.doi.org/10.1787/0ca0ca45-en.

OECD (2017), "Strengthening the effectiveness and sustainability of international research infrastructures”, OECD Science, Technology and Industry Policy Papers, No. 48, OECD Publishing, Paris, https://dx.doi.org/10.1787/fa11a0e0-en.

OECD (2013), Challenges and Opportunities for Innovation through Technology: The Convergence of Technologies.

OECD (2013), Knowledge Networks and Markets, OECD Publishing, Paris, https://doi.org/10.1787/5k44wzw9q5zv-en. 
Robinson, D., A. Lagnau and W. Boon (2019), "Innovation pathways in additive manufacturing: Methods for tracing emerging and branching paths from rapid prototyping to alternative applications", Technological Forecasting and Social Change, Vol. 146, http://dx.doi.org/10.1016/j.techfore.2018.07.012.

Robinson, D., A. Rip and V. Mangematin (2007), “Technological agglomeration and the emergence of clusters and networks in nanotechnology", Research Policy, Vol. 36/6, http://dx.doi.org/10.1016/j.respol.2007.02.003.

Teece, D. (2010), "Business models, business strategy and innovation”, Long Range Planning, Vol. 43/2-3, http://dx.doi.org/10.1016/j.lrp.2009.07.003.

Zott, C., R. Amit and L. Massa (2011), “The Business Model: Recent Developments and Future Research", Journal of Management, Vol. 37/4, pp. 1019-1042, http://dx.doi.org/10.1177/0149206311406265. 


\section{Annex}

\section{Austria: Austrian Smart Systems Integration Research Centre (ASSIC)}

\section{Platform Name and Description.}

The "Austrian Smart Systems Integration Research Centre" (ASSIC) is a so-called Competence Centre for Excellent Technologies (COMET) and located in Carinthia, Austria. ASSIC focuses on applied research in three main research areas in the field of intelligent system integration of micro- and nanoelectronics components: (1) microsystems technology (sensor elements): innovative nano and micro-sized microsystem technology components and associated manufacturing processes; (2) Heterogeneous integration (sensor modules): combines all components for sensors, electronics, data processing, wireless communication and power supply into one microsystem; (3) intelligent system solutions (sensor systems): includes the overall development, the connection of different technologies, the structure as well as the corresponding interfaces to the environment and the adaptation to the respective application.

ASSIC brings together 15 industrial partners (both SMEs and large industrial companies) and ten scientific partners; six are international ones. The partners cover the whole technological value chain. Currently, ASSIC has 131 employees whereof 103 are scientists. The non-university Research Centre Silicon Austria Labs (SAL) is the legal entity of ASSIC. SAL is a limited liability company with different shareholders. The competence centre was launched as Carinthia Tech Research in 1998 (under the Kplus Competence Centre Programme). The current funding period under the national COMET programme ends in 2022.

\section{Parent Policy Initiative.}

COMET-Centres are strategically oriented research programs jointly defined by companies and scientific partners. They aim at stimulating new research ideas, encourage technology transfer and strengthen innovative capacities of companies, and should initiate new product, service and process innovations.

COMET-Centres are funded through the national COMET-programme. A consortium consists of at least one scientific partner and at least five companies. The funding period of eight years is divided into two phases, each lasting four years. COMET-Centres (here K1) are financed by $40 \%-55 \%$ public funding, at least $5 \%$ by scientific partners, and at least $40 \%$ by companies; federal funding may not increase the amount of EUR 1.7 million per year, and provincial funding may not increase the amount of EU 0.85 million per year.

The competence centres programmes are internationally recognised as best-practice model and have been among the most successful technology policy initiatives in Austria.

\section{Stated Aim or Mission}

Based on the mission "We bring technologies to applications" ASSIC aims at achieving outstanding results, both with scientific excellence and economic value, to foster invention and innovation as a bridge builder between science and industry and to establish ASSIC as a renowned technology partner. 


\section{Funding}

The COMET Centre ASSIC is funded by the Austrian Federal Ministry for Transport, Innovation and Technology, the Austrian Federal Ministry for Digital and Economic Affairs as well as the Provinces of Styria and Carinthia. The Austrian Research Promotion Agency is in charge of the coordination of the whole funding as well as legal requirements of the Centre. The contribution of the industry partners $(\geq 40 \%)$ has to be paid in cash, whereas scientific partners can contribute up to $100 \%$ with in-kind activities. ASSIC's total costs amount EU 18.4 million for the first funding period (2015-2018), and EUR 20.4 million for the second one (2018-2022).

\section{Access}

Access, in the sense of becoming a partner of the COMET Centre, is provided in the application phase. Companies of any legal form and institutions of research and knowledge dissemination are eligible to participate. Applications have to be submitted for the first funding period. The granting of a second funding period is conditional on a successful midterm evaluation. The research programme defined jointly by science and industry has to create substantial added value as a result of cooperation and joint strategic orientation. Following the strategic focus, several research areas are defined, which consist of individual projects. The partners may cooperate within single-firm, multi-firm or strategic projects. The participation is evidenced by a "Letter of Commitment" including the relevant contribution (cash/in-kind). Rights and obligations of the partners are regulated in an agreement.

Due to the fixed framework, over the programme period a new partner may only join if another one gets out. The obligatory financial contribution of scientific and industrial partners may represent a barrier for participation; especially for international partners or smaller SMEs.

\section{Infrastructure}

ASSIC's infrastructure consists of optical, chemical, electrotechnical and mechanical equipment, simulation software and hardware for fluidic, optical, mechanical or magnetic topics as well as a cleanroom. This infrastructure can be used by the partners, provided that they are familiar with the laboratory rules and the handling of the devices. In general, partners use their infrastructure mutually. The utilization of infrastructure complies with the legal requirements defined by the EU. For the usage of infrastructure during contract research as well as for external users the costs reflect market prices.

Additionally, organizational structure as well as management expertise from SAL is provided to the partners of ASSIC.

\section{Intellectual Property Rights}

The COMET-Agreement regulates general IPR conditions and serves as a basis for more detailed IPR regulations within Cooperation Agreements on a project basis. Unless otherwise stated, IPR belongs to the Centre ASSIC. But in general it is agreed, that for instance in company projects (single-firm and multi-firm projects) the companies become the right of first refusal. For strategic projects, where only research institutes are involved, patent rights are usually shared among the involved parties. It is inevitable to define Intellectual Property Rights within the Cooperation Agreements in advance. 


\section{Data (ownership and sharing)}

ASSIC has strict data regulations. For instance, only secure connections (such as Secure File Transfer Protocol) may be used for the transfer of data.

\section{Public Private Collaboration.}

ASSIC fosters a cooperation between leading Austrian industrial partners and research institutes as well as international partners along the whole technological value chain. As ASSIC has been conducting its research in the same area for more than 20 years, the researchers know the respective scientific as well as industrial community very well. There are multi-firm projects with more than one industrial partner as well as single-firm projects with only one industrial partner. Overall, there is a strong collaboration between the partners, especially with the long-term partners.

For strategic, advisory and supervisory tasks certain boards are installed, like Strategy Board (five persons from science and industry as well as three shareholders; meetings on a semi-annual basis, discussion of strategic plans and equipment as well as partner selection), or General Board (representative of each partner and funding bodies, annual meetings).

\section{Education}

ASSIC supports its employees towards habilitation. Some of the researchers also teach at universities and technical colleges.

\section{Standardization}

ASSIC is participating in standardization processes within specialized research areas, in which the Centre has profound knowledge and conducts a lot of research. These participation activities are mainly based on a cooperation with European Standardization Bodies.

\section{Measures of activity}

In order to measure success and impact of the COMET Centre, ASSIC has defined several Key Performance Indicators (KPIs), most of them are required by the Research and Promotion Agency (FFG). Examples for these KPIs are:

Total number of publications in relevant journals ( 62 peer reviewed publications within the first funding period)

Number of patents, licenses, prototypes (19 patents and 46 prototypes within the first funding period)

Number of initiated products, processes and services

Number of spin-offs

Number of planned additional company partners / scientific partners

Number of $\mathrm{PhD}$ thesis, master thesis, bachelor thesis and habilitation

Number of invention disclosures (20-25 per year)

Number of international partners, etc. 
For ASSIC internally the number of invention disclosures plays an important role. Generally, KPIs and other criteria are monitored and evaluated in annual report audits, in a mid-term evaluation as well as in an ex-post evaluation.

\section{Stage of research, development, or commercialisation}

ASSIC mainly conducts research between the Technology Readiness Levels (TRL) 2.5 and 6. A strong focus lies on applied research, which requires strong project orientation as well as strong industrial orientation within the COMET Centre. However, strategic research projects are characterised by a high degree of novelty and excellence and are based on the COMET's long-term objectives. Such research is generally far from development and implementation.

\section{Safety and regulation}

During the R\&D activities of ASSIC all relevant environmental, health and safety regulations are complied with.

\section{Technology trends}

ASSIC is strongly engaged in Key Enabling Technologies; future fields of applications are Digitalization, Internet of Things, Smart Cites, Smart Health, etc. Technological trends are for instance the integration of system intelligence into sensors, or functionality of products. Special functionalities requested by potential users already lead to new technology developments.

\section{Summary Statement}

ASSIC's collaborative research is strengthening science and industries to develop intelligent and marketable products and thus create sustainable jobs. ASSIC fosters interdisciplinary cooperation along the whole value chain and generates a culture of "open innovation". With the COMET Centre ASSIC Austria plays an important role in the European micro- and nanotechnology R\&D sector. 


\section{Austria: Polymer Competence Centre Leoben (PCCL)}

\section{Platform Name and Description}

The "Polymer Competence Centre Leoben" (PCCL) is a so-called Competence Centre for Excellent Technologies (COMET) and currently the leading Austrian "centre of excellence" for cooperative research in the fields of polymer engineering and sciences. There are five different main research areas which specialize on (1) the development of structural applications, (2) smart materials, (3) functional polymers, (4) elastomer technologies and process optimization, and (5) simulation and modelling. All research activities are characterized by a strong focus on performance and functionality of polymer products. Resulting applications are used in a wide range of industries, from automotive, aerospace and packaging to solar and photovoltaics.

The Centre counts 18 scientific partners and 45 industrial partners; 23 are international ones. PCCL itself has 110 employees (78 full-time equivalent) from 14 different nations and has its main location in Leoben, Styria, Austria. PCCL as the legal entity of the COMET Centre is a limited liability company with different shareholders. PCCL ${ }^{1}$ was founded in 2002 as a Kplus Competence Centre (former COMET-Centres).

\section{Parent Policy Initiative}

COMET-Centres are strategically oriented research programs jointly defined by companies and scientific partners. They aim at stimulating new research ideas, encourage technology transfer and strengthen innovative capacities of companies, and should initiate new product, service and process innovations.

COMET-Centres are funded through the national COMET-programme. A consortium consists of at least one scientific partner and at least five companies. The funding period of eight years is divided into two phases, each lasting four years. COMET-Centres (here K1) are financed by $40 \%-55 \%$ public funding, at least $5 \%$ by scientific partners, and at least $40 \%$ by companies; federal subsidies may not increase the amount of EUR 1.7 million per year, and state subsidies may not increase the amount of EUR 0.85 million per year. ${ }^{2}$

The competence centres programmes are internationally recognised as best-practice model and have been among the most successful technology policy initiatives in Austria.

\section{Stated Aim or Mission}

PCCL's mission is to become an internationally leading Centre in the field of polymer sciences and, consequently, achieving world-class scientific standards. It carries out scientific research according to high international standards with the aim of increasing the innovative capacity of the partner companies involved; following the leading principle "from molecule structure to performance of components". ${ }^{3}$

\footnotetext{
${ }^{1}$ https://www.pccl.at/, accessed on 26.09.2019.

2

https://www.ffg.at/sites/default/files/allgemeine_downloads/strukturprogramme/COMET/2019102 4_COMET_factsheet_EN.pdf accessed on 26.09.2019.

${ }^{3}$ https://www.ffg.at/en/comet-competence-centers-excellent-technologies, accessed on 26.09.2019.
} 


\section{Funding}

PCCL is funded by the Austrian Federal Ministry for Transport, Innovation and Technology, the Austrian Federal Ministry for Digital and Economic Affairs as well as the Provinces of Styria, Lower Austria and Upper Austria. The Austrian Research Promotion Agency is in charge of the coordination of the whole funding as well as legal requirements of the Centre. The contribution of the industry partners $(\geq 40 \%)$ has to be paid in cash, whereas scientific partners can contribute up to $100 \%$ with in-kind activities. PCCL's total costs amounts EUR 22.6 million for the first funding period (2017-2020). ${ }^{4}$

\section{Access}

Access, in the sense of becoming a partner of the COMET Centre, is provided in the application phase. Companies of any legal form and institutions of research and knowledge dissemination are eligible to participate. Applications have to be submitted for the first funding period. The granting of a second funding period is conditional on a successful midterm evaluation. The research programme defined jointly by science and industry has to create substantial added value as a result of cooperation and joint strategic orientation. Following the strategic focus, several research areas are defined, which consist of individual projects. The partners may cooperate within single-firm, multi-firm or strategic projects. The participation is evidenced by a "Letter of Commitment" including the relevant contribution (cash/in-kind). Rights and obligations of the partners are regulated in an agreement. $^{5}$

Due to the fixed framework, over the programme period a new partner may only join if another one gets out. The obligatory financial contribution of scientific and industrial partners may represent a barrier for participation; especially for international partners or smaller SMEs.

\section{Infrastructure}

The infrastructure of PCCL and the partner/shareholder University of Leoben is set up complementary and used mutually. All other partners of the COMET Centre can also use this infrastructure, whereby costs are charged on an hourly basis (personnel and machine services). However, it is important to determine the framework conditions for the shared use in advance in cooperation agreements.

\section{Intellectual Property Terms}

The COMET-Agreement regulates general IPR conditions and serves as a basis for more detailed IPR regulations within Cooperation Agreements on a project basis. Unless otherwise stated, IPR belongs to the Centre PCCL.6 But in general it is agreed, that for instance in company projects (single-firm and multi-firm projects) the companies become

$4 \mathrm{https} / /$ www.ffg.at/comet-compentence-centers-excellent-technologies-k1-centers, accessed on 30.09.2019.

5

https://www.ffg.at/sites/default/files/allgemeine_downloads/strukturprogramme/02_k1call5_spezif ika.pdf, accessed on 01.10.2019.

https://www.ffg.at/sites/default/files/allgemeine_downloads/strukturprogramme/COMET/K2C4_A greementleitfaden.pdf. accessed on 30.01.2020. 
the right of first refusal. For strategic projects, where only research institutes are involved, patent rights are usually shared among the involved parties. It is inevitable to define Intellectual Property Rights within the Cooperation Agreements in advance.

\section{Data (ownership and sharing)}

Overall, PCCL complies with all requirements of the Data Protection Directive.

\section{Public Private Collaboration}

PCCL fosters interdisciplinary teams which cover the whole value chain; ranging from materials, to production, and up to recycling. There is a strong collaboration between the partners, especially with long-term partners. PCCL is well linked within the scientific and the industrial community of polymer sciences, making it easy to carry out joint projects. There are multi-firm projects with more than one industrial partner as well as single-firm projects with only one industrial partner. Large industrial partners of the Centre often serve as market observers and in further consequence give input on new fields of research or new required applications in the area of polymer sciences.

For strategic, advisory and supervisory tasks certain boards are installed, like Strategy Board (six persons from science and six from industry as well as shareholders; meetings on a semi-annual basis, discussion of strategic plans and equipment, etc.), or General Board (representative of each partner and funding bodies, annual meetings).

\section{Education}

Due to the close connection to the University of Leoben some master and doctoral theses are accompanied by the PCCL. Apart from that, education plays a rather subordinate role. However, due to different projects with the University of Leoben many of their polymer science students decide to work for the PCCL after finishing their studies.

\section{Standardization}

Some employees of PCCL are members of standardization committees for new specification standards. These participation activities are in cooperation with the International Standards Organisation (ISO), Austrian Standards and the like.

\section{Measures of activity}

In order to measure success and impact of the COMET Centre, PCCL has defined several Key Performance Indicators (KPIs), most of them are required by the Research and Promotion Agency (FFG). Examples for these KPIs are:

- Total number of publications in relevant journals (30-40 peer reviewed publications annually)

- Number of patents, licenses, prototypes (on average 18 patents within 4 years)

- Number of initiated products, processes and services

- Share of strategic research projects in entire research programme

- Number of spin-offs

- Number of planned additional company partners / scientific partners

- Number of PhD thesis, master thesis, bachelor thesis and habilitation 
- Number of international partners, etc.

KPIs and other criteria are monitored and evaluated in annual report audits, in a mid-term evaluation as well as in an ex-post evaluation. ${ }^{7}$

\section{Stage of research, development, or commercialisation}

PCCL covers a broad Technology Readiness Level (TRL) spectrum with its research activities, from basic research up to prototype development (TRL 6). However, strategic projects are characterised by a high degree of novelty and excellence and are based on the COMET's long-term objectives. Such research is generally far from development and implementation.

\section{Safety and regulation}

During the R\&D activities of PCCL all relevant environmental, health and safety regulations are complied with.

\section{Advanced materials}

Advanced materials play an important role in terms of optimization of the functional properties of plastics (e.g. optics, electronic). To a certain extent, nanomaterials are used to achieve these objectives. Moreover, additive manufacturing is used for specific smart materials.

\section{Digitalization and $A I$}

Digitalization is not a central topic within PCCL. There are some projects addressing the topics of Artificial Intelligence (AI), Machine Learning and Internet-of-Things in the field of processing. However, AI may play an increasing role in the next funding phase.

\section{Technology trends}

Future research topics range from thermally conductive polymers for microelectronics, to photovoltaics systems for the energy sector, up to sustainability issues, where waste disposal is of particular importance. Prediction of haptic properties of a component is another specific future research topic of PCCL.

\section{Summary Statement}

The application-oriented COMET-Centre PCCL fosters an interdisciplinary collaboration along the entire value chain of polymers between science and industry. As a result of mutual learning and understanding new research questions are stimulated as well as the innovative power in industry is strengthened. Overall, an increased international visibility can be achieved.

7

https://www.ffg.at/sites/default/files/allgemeine_downloads/strukturprogramme/evaluierungskonz ept_comet_2016_final_0.pdf, accessed on 30.09.2019 


\section{Canada: Materials for Clean Fuels Challenge Program}

\section{Platform Name and Description.}

Launched in early 2020, the Materials for Clean Fuels Challenge Program is a 7-year \$57M collaborative research program aimed to develop technology to decarbonize Canada's oil $\&$ gas and petrochemical sectors. It brings together Canada's national labs at the National Research Council (NRC) with academic and small-medium enterprise (SME) partners. The program seeks to develop high-risk, high-reward technologies at a low TRL (1-5) towards prototype and demonstration. There is a strong emphasis on catalyst and membranes materials (and associated devices) for artificial photosynthesis and renewable fuels/chemical feedstock production. The program focuses primarily on three themes $\mathrm{CO} 2$ conversion, industrial $\mathrm{H} 2$ production, and AI-accelerated materials discovery. NRC is currently building new capabilities in Toronto on "automated materials discovery platforms", combining AI and robotics to accelerate the pace of materials discovery. The program is national in scope but is based primarily at NRC's research labs in Toronto, Vancouver, and Ottawa. Collaborators include professors from the University of Toronto, University of British Columbia, McMaster University, University of Calgary, McGill and more. SMEs based in Canada's cleantech hubs (Vancouver, Calgary, and Toronto) are also represented.

\section{Parent Policy Initiative}

Through Budget 2018, the Government of Canada announced an ongoing annual investment of $\$ 108$ million to foster a "re-imagined" $\mathrm{NRC}$ - one that is at the centre of research excellence and collaboration, bringing together the best innovative minds to deliver solutions and breakthroughs that matter to Canadians. The Collaborative R\&D Initiative extends the ability of the NRC research centres to work with external collaborators who possess complementary capabilities on multi-party $\mathrm{R} \& \mathrm{D}$ programs that tackle major economic, social and environmental challenges facing Canada, while stimulating business innovation. Implemented by highly-dynamic teams that combine a diverse mix of post-secondary, industry and government researchers, these collaborative R\&D programs aim to generate game-changing scientific discoveries and technological breakthroughs.

The Materials for Clean Fuels Challenge Program is one such collaborative research program in support of the Pan-Canadian Framework on Clean Growth and Climate Change.

\section{Stated Aim or Mission}

Develop transformative technologies to sustainably transition Canada's energy, chemical, and industrial sectors to a low-carbon economy.

To collaborate with leaders in academia and industry to catalyze the discovery and development of materials for early-stage, high-risk technologies to decarbonize Canada's oil and gas and petrochemical sectors.

\section{Funding}

The total funding is split between NRC internal funds and external "Grants \& Contributions" (Gs\&Cs). Gs\&Cs is funding that must be spent externally to the Canadian government. This money (in total $\$ 20.3 \mathrm{M}$ ) is specifically provided to academics or SMEs to support collaborative research in the form of student stipends, materials/operating costs, 
and equipment. The remainder of the funds $(\$ 37.1 \mathrm{M})$ are $\mathrm{NRC}$ contributions to the projects including labour, facility, and operating costs.

Projects are expected to be between $\$ 200 \mathrm{~K}$ to $400 \mathrm{~K}$ per year in Gs\&Cs to a collaborator matched with $\$ 200 \mathrm{~K}$ to $\$ 400 \mathrm{~K}$ in $\mathrm{NRC}$ in-kind contribution for a total project value between $\$ 400 \mathrm{~K}$ and $\$ 800 \mathrm{~K}$ per year in phase 1 . In later phases projects are expected to rise to up to $\$ 1-2 \mathrm{M}$ per year with collaborator cost-share.

\section{Access}

In order for a collaborator to qualify for Gs\&Cs funding they must be either a SME or an academic researcher. Each project is collaborative, meaning an external co-lead (SME or professor) and in internal NRC co-lead (NRC researcher). Projects are selected through a combination of directed calls and an open call competition. Successful projects are selected based on scientific merit, alignment with NRC competencies, and potential for impact by an Advisory Board consisting of NRC and external stakeholders (industry, international researchers, etc.) The Program is marketed through the NRC website and other media channels including official announcements, email blasts, stakeholder engagement meetings, and conferences.

\section{Intellectual Property Terms}

The Challenge Program is expected to create impactful new IP and also support the development and exploitation of existing IP, across all of the Program's themes. While each technology will be assessed on a case-by-case basis, commercialisation by Canadian companies and access to Canadian end-users will be general objectives that the Program will strive for.

Furthermore, it is anticipated that the Program's collaborators, both industry and academic, will bring significant background IP to this initiative. Many of the collaborators have been identified because of their potential breakthrough technologies, and the Challenge Program will work in partnership to further develop and exploit our collaborators' IP.

\section{Data (ownership and sharing)}

Data ownership and sharing is negotiated on a project-by-project basis. The majority of projects will be involve open-source data or publication in public peer-reviewed journals.

\section{Public Private Collaboration}

The Program will collaborate with the leading academic research groups from universities across Canada (University of Toronto, University of British Columbia, McGill, University of Calgary, University of Alberta, McMaster, etc.), disruptive cleantech SMEs (e.g. Carbon Engineering, Hydrogenics, Ionomr, etc.), other governmental organizations such as National Resources Canada (NRCan), and large multi-national enterprises in the energy and chemical sectors. The Collaboration Centre in Clean Energy Materials (CC-GEM) between NRC and the University of Toronto is expected to be a key vehicle for collaboration. The low TRL nature of the program is geared toward more pre-competitive development.

The Program seeks to provide an integrating and coordinating role, with supporting funding and networks, to harmonize these efforts towards well-defined and focused GHG emissions reduction objectives. The program will be positioned to leverage existing NRC facilities and expertise from a number of NRC Research Centres (Energy, Mines and Environment, 
Security and Disruptive Technologies, Nanotechnologies, Advanced Electronic and Photonics, Digital Technologies, Automotive and Surface Transportation, and Metrology) and national and international networks with other research organizations, SME support, industry influence, and international collaboration initiatives with Germany, the UK and Japan. The program will also build on other Government initiatives of NRCan Canmet laboratories, the Clean Growth Hub, Mission Innovation and others.

\section{Education}

Education is a part of the general communications strategy at the National Research Council. The Program focuses mainly on stakeholder engagement with industry and other governmental departments. The goals are to educate the larger cleantech ecosystem on the potential for renewable electrochemical technologies. Gender, Diversity and Inclusivity considerations are also important for the NRC.

\section{Measures of activity}

The program will measure activity through traditional quantitative metrics such as \# of projects, \# publications, patents, IP articles generated, HQP trained, SMEs engaged, and revenue earned.

Stage of research, development, or commercialisation. The program is currently targeting low TRL technologies (1-5) and targeting an increase of these technologies to mid TRL (46 ) by the end of the Program lifetime. Every thrust in the Program has potential for commercialisation as the materials and technologies developed herein have potential impact in the energy industry. Mechanisms for commercialisation include supporting a start-up company, spinning off a company from the program, licensing the materials, or selling access to datasets and algorithms.

\section{Safety and regulation}

The National Research Council places the highest priority on safety. The national lab facilities are equipped to deal with any and all safety need/requirements arising from the research conducted by the program. The expected environmental impact area is towards GHG emissions reductions in support of Canada's mission to meet our Paris Climate Accord targets.

\section{Societal Implications}

Canada needs to reduce 716 megatons of carbon dioxide emissions per year to reach its goal of net-zero emissions by 2050. Electrification and energy efficiency alone is not enough to meet our targets. There do not yet exist scalable technologies to produce zeroemission industrial chemicals and transportation fuels. This program is focused on developing these technologies to transition Canada to a low-carbon economy.

\section{Converging Technologies}

An objective of the network is to develop a clear vision for how it supports other national research priorities such as artificial intelligence, quantum, and medical innovation, and how it can evolve and address these and other areas going forward. 


\section{Summary Statement}

The mission-driven Materials for Clean Fuels (MCF) Challenge program is focused on advancing high-risk, high-reward technologies to produce feedstock chemicals and fuels from air and water rather than from fossil-based resources.

Working with the best in Canada from academia and industry, it will catalyze development of materials for renewably-powered $\mathrm{CO} 2$ conversion and hydrogen production using artificial intelligence and robotics to accelerate this discovery. 


\section{European Commission: European Pilot Production Network}

\section{Platform Name and Description.}

The overall goal of the European Pilot Production Network is to boost the European competitiveness through the exploitation of the existing European pilot line production facilities (across Europe) in the area of nanotechnology and advanced material technologies by creating a network of fully connected and collaborating pilot lines and boost the effectiveness and the efficiency of existing (and future) pilot line facilities and by creating a digital ecosystem acting as an interactive marketplace for professional members.

Presently the network comprises over 170 pilot productions in 19 European countries.

\section{Parent policy initiative}

The parent policy initiative is the Europe 2020 strategy for smart, sustainable and inclusive growth, of which the Innovation Union, one of its seven flagships, is the most relevant here. The final report of the Key Enabling Technologies (KETs) High Level Group from 2015 is the basis for more targeted actions in the area of nanotechnologies and advanced materials. ${ }^{8}$

Furthermore, the work on pilot lines and Open Innovation Test Beds (OITBs) has led to the development of a European Commission Staff Working Document on Technology Infrastructures, adopted in April 2019. ${ }^{9}$

\section{Stated Aim or Mission}

The overall goal is to boost the European competitiveness through the exploitation of the existing European pilot line production facilities (across Europe) in the area of nanotechnology and advanced material technologies by creating a network of fully connected and collaborating pilot lines and boost the effectiveness and the efficiency of existing (and future) pilot line facilities and by creating a digital ecosystem acting as an interactive marketplace for professional members.

\section{Funding}

The EPPN is funded for three years with an amount of $€$ 976,812.63 through the European Funding programme for Research and Innovation, Horizon 2020, which is the financial instrument implementing the Innovation Union. After the end of public financing the platform aims at being financially sustainable.

\footnotetext{
${ }^{8} \mathrm{https} / / /$ ec.europa.eu/docsroom/documents/11082/attachments/1/translations/en/renditions/native

9 https://publications.europa.eu/en/publication-detail/-/publication/0df85f8b-7b72-11e9-9f0501aa75ed71a1
} 
Access

Different access levels to the platform are foreseen, ranging from free access with limited functionality to full service access with a yearly fee. It is open to all actors in the field.

\section{Intellectual Property Terms}

IPR and licensing arrangements are made on individual basis between the members of the platform who decide to work together.

It should be noted that the technology of the digital platform itself (i.e. the connecting tool) belongs to the EPPN consortium

\section{Data (ownership and sharing)}

EPPN has no ownership of research/product data produced. The ownership stays with the users who can decide for each data set if they want to share it or not.

However, EPPN owns the data gathered from the use of the digital EPPN platform.

\section{Education}

The platform is business oriented and one of the services foreseen is advice on training.

\section{Stage of research, development, or commercialisation}

The overall aim of the platform is to enable SME's and industry to get connected with stateof-the-art infrastructure and services to bring new technology developments faster to the market, i.e. moving up the last TR levels.

\section{Role of digitalization}

The entire platform is digital based, to build communities, allow matchmaking, connect potential partners and exchange ideas. 


\section{European Commission: Innovation test bed for lightweight embedded electronics (LEE BED)}

\section{Platform Name and Description.}

LEE-BED is an Open Innovation Test Bed (OITB) for the development and production of nanomaterials for lightweight embedded electronics. The service providers of the platform are located in DK, UK, NL, SE, ES, DE, and FR. They provide equipment and competencies in techno/economic modelling, nanomaterial pilot lines, formulation pilot lines, component pilot lines, in-line characterisation, and in knowledge transfer. The project started 01 January 2019, with a duration of four years.

\section{Parent policy initiative}

The parent policy initiative is the Europe 2020 strategy for smart, sustainable and inclusive growth, of which the Innovation Union, one of its seven flagships, is the most relevant here. The final report of the Key Enabling Technologies (KETs) High Level Group from 2015 is the basis for more targeted actions in the area of nanotechnologies and advanced materials. ${ }^{10}$

Furthermore, the work on pilot lines and Open Innovation Test Beds (OITBs) has led to the development of a European Commission Staff Working Document on Technology Infrastructures, adopted in April 2019. ${ }^{11}$

\section{Stated Aim or Mission}

The overall goal is to de-risk and accelerate the development and manufacturing of nanomaterials and lightweight embedded electronics for the benefit of European industry. This aim will be achieved by building a European infrastructure for rapid development and pilot production of nanomaterial, inks, adhesives and composites as well as digital based pilot production lines. LEE-BED will unify the entire value chain from raw materials to embedded electrical components, providing tailored solutions for European entrepreneurs, start-ups, SMEs and large enterprises, with the main objective of going from concept to prototype within six months. Unique to LEE-BED will be the development of tailored services, including technical, business, patent mapping, safety and life-cycle analysis modelling. LEE-BED will also provide funding services for LEE-BED access to SMEs and post-project capital.

\section{Funding}

LEE-BED is funded for four years with an amount of $€ 10,696,766.25$ through the European Funding programme for Research and Innovation, Horizon 2020, which is the financial instrument implementing the Innovation Union. The largest part of this funding is used to upgrade the pilot-line and characterisation facilities during the four years.

\footnotetext{
${ }^{10} \mathrm{https}$ //ec.europa.eu/docsroom/documents/11082/attachments/1/translations/en/renditions/native 11 https://publications.europa.eu/en/publication-detail/-/publication/0df85f8b-7b72-11e9-9f0501aa75ed71a1.
} 
The project has developed already at the proposal stage a draft business plan laying out how to achieve the required financial sustainability after the end of the financing through Horizon 2020.

\section{Access}

The access conditions will have to follow the guidelines published by the European Commission for the OITBs. ${ }^{12}$ The guidance specifies that: Open Access in [the context of OITBs] means that any interested user, from Europe and beyond, can access the test beds' facilities, capabilities and services independently of whether this user is part of an Open Innovation Test Beds Horizon 2020 consortium or not. Access should be granted at fair conditions and pricing and with transparent and mutual obligations with regards to, for instance, security, safety and intellectual property rights.

\section{Intellectual Property Terms}

The specific terms regarding aspects such as intellectual property measures and ownership rules on respective rights and obligations, including liability and confidentiality arrangements; data management and protection; and defining general access terms and conditions will be developed in the course of the project, respecting the guidelines of the European Commission.

\section{Education}

Training for users in areas such as IPR and data management will be part of the services provided by this OITB.

\section{Standardization}

The test bed will not only ensure compliance of developments and results with existing standards. It will also provide support in the proposal of new standards relevant to their technology area.

\section{Measures of activity}

Key Performance Indicators will be defined to monitor and test the developed business model.

\section{Stage of research, development, or commercialisation}

The overall aim of the platform is to enable SME's and industry to get connected with stateof-the-art infrastructure and services to bring new technology developments faster to the market, i.e. moving up the last TR levels.

\section{Safety and regulation}

Similarly to standardisation, the test bed will ensure that developments and results are EHS compliant.

12 https://ec.europa.eu/research/participants/data/ref/h2020/other/guides_for_applicants/h2020-imac-innotestbeds-18-20_en.pdf 


\section{Japan: Nanotechnology Platform Japan (NPF)}

\section{Platform Name and Description.}

Nanotechnology Platform Japan (NPF) started its activity as a user facility network in 2012 under the sponsorship by MEXT (Ministry of education, science and technology) as a tenyears program. It is expected to work as a nanotechnology platform for academia and industry, consisting of 25 research institutes including universities and national laboratories distributed throughout the nation. NPF consists of the Leading Institute that oversees the whole and three platforms (nano-characterization platform, nano-fabrication platform, molecular design \& synthesis platform). Each of 25 constituent research institutes belongs to one or more of these platforms. The numbers of personnel of researchers, technical staff hired by constituent research institutes, and technical and administrative staff hired by the national program are $350,250,250$, respectively.

\section{Parent Policy Initiative}

The 4th Science and Technology Basic Plan in Japan (2011 2015) points out the importance of the user facilities and also requires the strengthening of national infrastructural network for R\&D. MEXT started NPF program as a user facility network in 2012 according to the Basic Plan.

\section{Stated Aim or Mission}

The aim of NPF is to establish a reliable research infrastructure (Platform) for scientific innovation by the alliance of the institutes which have cutting edge equipment and research know-how. Through this program, it is promoted for any of researchers from young to industrial one to do the shared-use of the equipment, and to solve the urgent problems in science and technology. NPF provides the following benefits to researchers,

- Shared-use of equipment with which anyone can do nanotech-researches at any place

- Promotion of interactive researches and the integration of technologies

- Technical improvement of talented researchers

\section{Funding}

NPF's total activity cost is about 5 billion yen, of which 2.5 billion yen is covered by the expenditure from 25 constituent research institutes, 1.0 billion yen by the usage fee for their technical services, and 1.5 billion yen by the funding money from the national project. The breakdown of activity costs varies by constituent research institutions. For example, the usage fee income of MEMS Facility at Tohoku University, which is actively engaged in joint research with companies and universities, covers nearly $80 \%$ of the total activity cost.

\section{Access and Intellectual Property Terms}

A user who has already clear idea of requesting tasks asks cooperation to an appropriate constituent research institute. A user who has not determined the research institute to be requested and wants to start by consulting the research contents consults with any of PFs or Leading Institute. Cooperation requests are classified as (1) usage consultation, (2) technical consultation, (3) use of equipment through operating it by user's self, (4) commissioned research requesting operation by NPF engineers, (5) collaborative research 
between a user and NPF, and those are charged except the usage consultation according to the level of the requesting research content.

The patent born in (2), (3) and (4) is owned by the user, and the patent born in (5) is shared. NPF's activities are basically technical support for users, not necessarily for patent acquisition.

\section{Data}

The ownership of data is handled basically in the same way as that of intellectual properties.

\section{Public Private Collaboration}

Users can choose to make their research content open or not. The price of the equipment usage and technical staff's support fee differs depending on whether it is open or not, and it will be higher if it is not open. If users choose to be open, they will be obliged to make a report, which will be made open. The use on the premise of disclosure corresponds mostly to the use by public institutes of universities and national laboratories, and the use on the premise of non-disclosure corresponds mostly to the use by industries. Their ratio is currently $65 \%$ (use on the disclosure premise): $35 \%$ (use on the non-disclosure premise).

\section{Education}

NPF has its own programs of schooling and training for students and technical staffs using NPF facilities, and exchanging information and networking for younger researchers. NPF holds the awarding system of technical level certificate for technical staff in order to provide motivation of their skill-up and construction of career path to them. Three levels of job titles, Expert, Highly specialized technical staff, and Specialized technical staff are assigned to outstanding technical staff depending upon their skill level.

\section{Standardization}

No special activities are conducted regarding standardization in the NPF.

\section{Measures of activity}

The user satisfaction, the number of service projects, usage fee income of services, and the numbers of papers, oral presentations, patent applications and awards are important evaluation items. The number of projects supported by the NPF and the usage fee income are increasing with years. The numbers of related papers, those citations, and patents are also increasing. A quarter of total projects are the ones conducted by the industry requirements. However, we think it is more important that the 25 research institutes that make up NPF respond to the user's requests and form the best group to tackle them and execute the task collaboratively. It makes possible to achieve high-quality research results that cannot be done by a single institute.

\section{Stage of research, development, or commercialisation}

All the stages of development are supported in the NPF from the scientific research mainly conducted by academia to the commercialisation by industry. Even in the commercialisation stage, NPF has made a great contribution to solve user's problems such as optimization of process conditions, provision of optimal processes, and elucidation of 
causes of failure modes at a micro- and nano-scale. Industry users introduce innovative devices, components, and products to the market based on those knowledge.

\section{Safety / Regulation}

No special activities are conducted regarding safety and regulation issues in the NPF.

\section{Role of digitalization in the convergence enabled by the platform}

National Institute for Materials Science (NIMS), serving as the Leading Institute, also has a function as a centre for material development and exploration services using materials informatics with a large material database. Although discussions are underway to provide comprehensive services by adding the process data and material evaluation data produced by NPF, the confidentiality of these material data is high, and it has become an obstacle to proceeding with sharing those data and analysing them using informatics tools.

\section{Others (Bottlenecks and challenges in the activity of the platform)}

When the NPF started, the equipment was renewed significantly by the special budget in the first year, but it is not easy to purchase or renew the equipment with the normal budget. Eight years have passed since the start of NPF in 2012, and the equipment is getting aging. Renewing the old equipment is a major issue and also a challenge. The second one is how to secure excellent technical staffs on a regular basis and how to maintain NPF activities sustainably. At present, NPF employs about 250 technical staff by the national program, but they are limited-term employees and their jobs are not stable in the long-term. 


\section{Portugal: International Iberian Nanotechnology Laboratory (INL)}

\section{Platform Name and Description.}

International Iberian Nanotechnology Laboratory (INL), located in Braga (North of Portugal) - was founded by the governments of Portugal and Spain under an international legal framework to perform interdisciplinary research, deploy and articulate nanotechnology for the benefit of society. INL has seen growth in all numbers since it opened 5 years ago. To date, it gathers 430 people from 42 countries and different science backgrounds, working in 22 research groups in six general areas. It is an autonomous intergovernmental institution with international laboratory status that also has a start-up program and incubating facilities for hire. It offers competitive funding, excellent research enabling contracted scientific and technological research, development and innovation, worldwide connectivity and has plans to increase its international footprint. Moreover, INL fosters public engagement with its science and arts program by hosting artists in residence who create artistic expressions related to their experience and time spent as resident. Works that are publicly exhibited in installations in a gallery in Braga.

\section{Parent Initiative}

Portugal Science and Technology Strategy for the Nanotechnology Priority

\section{Stated Aim or Mission}

At INL scientists and engineers from all over the world work in a highly interdisciplinary environment and strive to make INL become a world-wide hub for the deployment of Nanotechnology addressing society's grand challenges.

\section{Access}

The INL Statutes (2007) anticipate the possibility of opening INL to the membership of other countries and to the participation of institutions and experts from all of the world, with the objective of establishing an international pole of excellence, developing partnerships with higher education institutions and industry transferring knowledge with added value, generating employment and training specialized professionals.

\section{IP, Data owning and sharing}

IP is regulated by agreements case by case.

\section{Public-Private Collaboration}

INL follows a multidisciplinary approach to Innovation though the I3 (Invention, Integration, Innovation) model, which stimulates the cooperation and engagement among stakeholders in the generation of novel ideas that ca Turn into innovation.

This approach includes an effective form of co-operation and co-creation among organisations, which promotes the integration of stakeholders in the development process, who jointly co-create mutually valuable results, for the benefit of society. 


\section{Education}

The INL has developed partnerships with higher education institutions and industry transferring knowledge, generating employment and training specialized professionals

\section{Performance Indicators}

INL is strongly involved in regional, national, and international initiatives (including 14 regional and inter-regional, 60 national and 21 EC-funded projects). Some of these are de facto platforms for co-creation, regulation, standards.

\section{Stage of research, development, or commercialisation}

The research programme comprises four strategic fields of application of nanoscience and nanotechnology: Food and Environment monitoring, ICT, Renewable Energy and Health.

\section{Safety and Regulation}

INL has participated in several regulation-oriented network projects, as EU's NanoReg and NanoReg2.

\section{Societal Implications}

It is an integral part of the mission of the INL to address societal challenges

\section{Converging Technologies}

Nanotechnologies are one of the better known examples of converging technologies. The INL is a multidisciplinary facility effectively focused on the interdiscipplinary approach to Research and Innovation issues. 


\section{Portugal: Collaborative laboratories (CoLABs)}

\section{Platform Name and Description.}

Collaborative Laboratories (CoLABs) are non-profit private associations or companies. Their main goal is to create skilled and scientific jobs in Portugal, both directly and indirectly, by implementing research and innovation agendas geared at creating economic and social value.

\section{Parent Initiative}

Portugal Science and Technology Strategy

\section{Stated Aim or Mission}

CoLABs must meet the challenge of enhancing the density of knowledge-based activities in the country by fostering the consolidation of collaborative practices between scientific, technological or higher education institutions and the social and economic fabric, namely businesses, the hospital and health care system, cultural institutions, and social organizations.

\section{Access}

Access is regulated by a call on a specific strategic theme. Approved consortia acquire the "Collaborative Laboratory" status that will provide access to specific future initiatives.

\section{IP, Data owning and sharing}

IP and data sharing are regulated by consortia agreements, having to obey to the principle of open science.

\section{Public-Private Collaboration}

CoLABs may include companies, non-corporate R\&I organizations, Higher Education Institutions (through their R\&D Units), Technological Interface Centers and other intermediate or interface institutions, business associations, other public administration organizations, and other partners within the productive, social or cultural fabric. No associate, partner or shareholder may hold less than $5 \%$ or more than $49 \%$ of the assets or share capital.

\section{Education}

Education and training of technical and scientific staff is among the objectives of a CoLAB.

\section{Performance Indicators}

Two CoLABs are focused on specific applications of advanced materials, among the 26 CoLABs already approved.

\section{Safety and Regulation}

It is part of the consortia obligations to take into account safety and regulations in their activities. 


\section{Societal Implications}

The CoLabs are intended to foster knowledge transfer to the Economy and Society.

\section{Converging Technologies}

Many of the CoLabs are multidisciplinary and tackle converging technologies (as it is the case of the two concerned here) 


\section{Portugal: University of Texas at Austin - Portugal Program}

\section{Platform Name and Description.}

The University of Texas at Austin - Portugal Program is a partnership program in Science and Technology between the Portuguese Foundation of Science and Technology (FCT) and the University of Texas at Austin (UT Austin), supported by the Ministry of Science, Technology, and Higher Education in close collaboration with the Council of Rectors of the Portuguese Universities (CRUP).

\section{Parent Initiative}

Portugal Science and Technology Strategy

\section{Stated Aim or Mission}

Its Mission is to address a number of knowledge areas where scientists and companies in Portugal engage with the University and other institutions in Texas in multidisciplinary research and technology transfer and commercialisation.

Launched in 2007, the partnership was renewed in 2018, towards a new decade until 2030. After ten years of joint collaboration, UT Austin and Portuguese institutions continue to develop a cooperative effort to promote a thriving research agenda, strongly aligned with the strategy of the country in the different scientific and technological areas.

\section{Funding}

tbd

\section{Access, Public-Private Collaboration, Education}

The program seeks to stimulate and reinforce the effective collaboration among researchers, faculty, students and companies through collaborative R\&D projects and highlevel education and training opportunities, while promoting and enabling a deeper involvement in the multidisciplinary network between Portugal and Austin.

Simultaneously, the engagement of technology firms and new entrepreneurial initiatives should continue and be reinforced through the University Technology Enterprise Network (UTEN), to prepare Portuguese researchers and innovators for scientific readiness for commercialisation success.

\section{Stage of research, development, or commercialisation}

The program activity currently focuses in five Areas: Advanced Computing, Medical Physics, Nanotechnologies, Space-Earth Interactions and Technology and Innovation and Entrepreneurship. The approach is through initiatives focused on Research, Education and Innovation. 
Figure 4. Overview of program areas and instruments

\begin{tabular}{|c|c|c|c|c|c|c|c|}
\hline \multicolumn{2}{|c|}{ Advanced Computing } & Medical Physics & \multicolumn{2}{|c|}{ Space-Earth Interactions } & Nanotechnologies & \multicolumn{2}{|l|}{ TIEIUTEN } \\
\hline \multicolumn{2}{|c|}{$\begin{array}{l}\text { High Performance } \\
\text { Computing, } \\
\text { Data Analytics } \\
\text { and Visualization }\end{array}$} & $\begin{array}{l}\text { Emerging Cancer } \\
\text { Therapies }\end{array}$ & \multicolumn{2}{|c|}{$\begin{array}{l}\text { Space Technologies } \\
\text { Sea } \\
\text { Climate } \\
\text { Clean Energy }\end{array}$} & \multirow[t]{2}{*}{$\begin{array}{l}\text { Materials } \\
\text { for New Markets }\end{array}$} & \multicolumn{2}{|c|}{$\begin{array}{l}\text { Technology } \\
\text { Innovation } \\
\text { Entrepreneurship }\end{array}$} \\
\hline research & & & education & & & innovation & \\
\hline \multirow{4}{*}{$\begin{array}{l}\text { Exploratory } \\
\text { Research } \\
\text { Projects }\end{array}$} & \multirow{4}{*}{$\begin{array}{l}\text { Strategi } \\
\text { Researc } \\
\text { Projects }\end{array}$} & & \multirow{4}{*}{$\begin{array}{l}\text { Advanced Training } \\
\text { Programs }\end{array}$} & \multirow{4}{*}{$\begin{array}{l}\text { Research } \\
\text { Exchanges }\end{array}$} & & Training & 气 \\
\hline & & & & & & Mentoring & $\frac{5}{2}$ \\
\hline & & & & & & \multicolumn{2}{|l|}{ Residency in Austin } \\
\hline & & & & & & Industrial affliates & \\
\hline
\end{tabular}

Source: provided by the case authors

\section{Safety and Regulation}

Taking into account safety and regulations issues is mandatory for FCT-funded projects.

\section{Societal Implications}

Thus initiative promotes the internationalization of PT I\&I and cross-atlantic cooperation.

\section{Converging Technologies}

The majority of program areas are multidisciplinary and tackle converging technologies (as it is the case of the two concerned here). 


\section{Korea: Nano-Convergence 2020 Program}

\section{Platform Name and Description.}

Nano-Convergence 2020 is a collaborate program of the Ministry of Science and ICT (MSIT) and Ministry of Trade, Industry and Energy (MOTIE) to support commercialisation of nanotechnology research outcomes to create new products and markets in the early stage. The program was launched in September 2012 and will be terminated by the end of 2020 .

\section{Stated Aim or Mission}

The program aims to commercialise patented nanotechnology in the public sector (universities, research institutes) by combining with market demand in the private sector, leading to new innovative in the field of nano-convergence technology.

\section{Funding}

For the nine-year program period from 2012 to 2020, the total budget was KRW 208.7 billion (KRW 143.7 billion from the government (KRW 46.1 billion from the MSIT, and KRW 97.6 billion from the MOTIE) and KRW 65 billion from the private sector,).

\section{Access}

A company with an idea for novel product(s) based on nanotechnology gives NanoConvergence Foundation (NCF) a proposal including business model (BM) that incorporates a joint research team (the IP-holding institute or other organization(s) required for commercialisation), target product, research budget, and the characteristics of target market such as volume or launching time. The company in charge of commercialisation should be ready to commercialise the IP into a new product in terms of facilities, experience, and marketing strategy together with financial strategy. As a prerequisite condition, the IP has to be research outcomes from the projects funded by government as well as it should be transferred to the private company prior to proposing a commercialisation plan.

\section{Intellectual Property Terms}

According to the intent to empower all authority and responsibility to the leading company for putting its all effort to commercialisation, all tangible and intangible outcomes, in principle, belong to the leading company. In case of evident contribution of participant(s), the outcomes can be shared under mutual agreement.

\section{Data (Ownership and Sharing)}

For efficient management of the Nano-Convergence 2020 Program, a management system measuring performance and outcomes is set up and updated periodically. Both research managers and program managers can enrol all information related to their performance in the predetermined forms in any time on this system and check their outcomes conveniently at a glance. It contains all information generated in the process of commercialisation (progress against quarterly targets, IP, job creation, sales, external activities, next quarter plans, challenges, etc.). 


\section{Public-Private Collaboration}

The Nano-Convergence Foundation provides a chance to the public sector (universities and research institutes) to introduce their nanotechnology-IP(s) to the private sector, which might be adequate and linked to idea of novel product. The NCF aims to support the IPs in the public sector to be commercialised matching with market demand in the private sector.

\section{Measures of Activity}

The Nano-Convergence 2020 Program aims to achieve the following tangible outcomes by the end of 2020: global star products having large share in the global market (4 cases), companies successfully commercialising the target products $(15$ cases $)$, basic nanotechnology converged with other technologies (40 cases), and nano-convergence technology globally acceptable (4 cases; see the following table for the definitions of these terms). In addition, sales volume from the commercialised as well as job creation are counted as a performance indicator for $\mathrm{R} \& \mathrm{BD}$ products together with patents and scientific publications

Table 1. Definition of Terminology Regarding Outcome Measures of the Nano-Convergence 2020 Program

\begin{tabular}{|c|c|}
\hline $\begin{array}{l}\text { Program mission } \\
\text { (Outcome measures) }\end{array}$ & Definition of Terminology \\
\hline $\begin{array}{l}\text { Global } \\
\text { star product }\end{array}$ & $\begin{array}{l}\text { Sets or parts providing key function }(s)^{*} \text { for the novel products } \\
\text { * Key functions refer to essential performance or parts that } \\
\text { differentiate novel products or world-class products with large } \\
\text { market share from rivals }\end{array}$ \\
\hline $\begin{array}{l}\text { Companies successfully } \\
\text { commercialising target products }\end{array}$ & $\begin{array}{l}\text { The companies commercialised their ideas into new products and } \\
\text { sold their products in the real market. }\end{array}$ \\
\hline 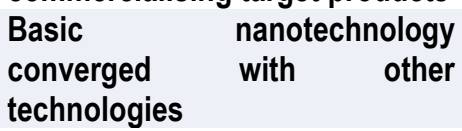 & $\begin{array}{l}\text { Package-type technology with a series of patents forming a portfolio } \\
\text { with more tha Three patents, protecting relevant products from } \\
\text { patent litigation }\end{array}$ \\
\hline $\begin{array}{l}\text { Nano-convergence technology } \\
\text { globally acceptable }\end{array}$ & $\begin{array}{l}\text { The technology holding the patent directly related to the key functions } \\
\text { of global star products }\end{array}$ \\
\hline
\end{tabular}

Source: developed by the case study authors

\section{Stage of Research, Development, or Commercialisation}

This program aims to complete a whole process of nanotechnology development from scratch to commercialisation through the collaboration of MSIT-MOTIE, leading to commercialisation of nanotechnology R\&D outcomes as early as possible.

\section{Other}

By the end of 2018, sales volume of KRW 470.3 billion - corresponding to $392 \%$ of government investments (KRW 119.9 billion)-were recorded. Furthermore, 613 jobs were created (KRW 5.1 per billion invested), and royalties paid for technology transfer amounted to KRW 7.1 billion. Lead time required for commercialising new idea was estimated to be shortened by 2.32 years from 4.86 years to 2.54 years in the NanoConvergence 2020 Program, indicating that the program practically acts as a platform for nanotechnology commercialisation. 
The Nano-Convergence 2020 Program model will be continued to cope with accelerating demand for innovation, a rapidly growing nanotechnology market, and the overall response to the social and economic demands of nanotechnology and a subsequent program modified in scope and capability is under examination.

\title{
11. Korea: Materials Design Platform
}

\section{Platform Name and Description.}

"Nano Materials Research on Platform" includes facilities (nano-fabrication facilities) and materials design platforms based on materials simulations, funded by the National Research Foundation (NRF) of the Ministry of Science and Information, Communication Technology (MSIT), and by the Korea Institute of S\&T Evaluation and Planning (KISTEP) of the Ministry of Trade, Industry and Energy (MOTIE). There are three materials design platforms: $N A N O F A B$ for nano-device simulations, $i B A T$ for Li ion battery materials design, and $q$ Cat for materials design for catalysis applications. The platforms have been developed with close collaborations among multiple government-funded laboratories, universities, and companies.

\begin{abstract}
"Nano Materials Research on Platform" also operates as a core infrastructure for generating, collecting, managing, and utilizing materials research data for big data applications. Specifically, in 2017, the Korean government initiated the National R\&D Data Infrastructure, which aims to provide a hierarchical data framework ranging from data-focused infrastructure to that of specific applications. This platform is also based on close collaborations among multiple research institutes including government-funded laboratories, universities, and companies.
\end{abstract}

\section{Parent Policy Initiative.}

Since 2010, both MSIT and MOTIE have made great efforts to establish the R\&D platforms as the major R\&D infrastructure. The efforts include plans of the National Nano Fabrication facilities and the Strategy for Nano Technology Industrialization (2015) with the plans for developing seven nano technologies: 3D nano electronic devices, environment nanosensors for IoT technology, nano-sensors for food safety, functional nano-fabrics, precious metal free nano catalysts, rare earth free nano materials, and a low energy consumption water treatment system. Four specific supporting plans have been also announced as follows: (1) to strengthen the support for the nanomaterials sector through National Nano Fabrication facilities, (2) to establish the computational nanoscience platforms, (3) to strengthen the nano safety assessment, and (4) to support the performance evaluation of nano products. Based on this strategic policy, the government of Korea has significantly strengthened support to develop materials design platforms ${ }^{1}$. In the "Proposal for strategic development policy of value-added-materials leading to new industries" published by the Presidential Advisory Council on Science and Technology (PACST) in 2016, the sustainable materials design platforms were again emphasized. ${ }^{2}$ In 2017, MSIT started to develop policy measures to enhance access to research data generated and accumulated in the universities, government-funded research institutes, and national R\&D facilities. Accordingly, in 2018, the "Strategy to Promote Sharing and Use of Research Data for 
Innovative Growth" was proposed for a systematic approach with multiple policy measures ${ }^{3}$.

\section{Stated Aim or Mission}

The goal of the R\&D platforms is (1) to accelerate industrialization of nanotechnology, and (2) to promote the process of materials development by advanced research tools including both experimental and computational approaches. The aim of the National R\&D Data Infrastructure is to promote sharing and utilization of research data generated and accumulated nationwide so that data-driven breakthrough in materials development is feasible.

\section{Funding}

The NRF and the KISTEP is financially supporting the materials design platform development project. About 9,480,000,000 KRW in total have been provided to the five projects since 2012 . From 2009 , one feasibility test project was supported by NRF with a total of $1,000,000,000 \mathrm{KRW}$ for three years.

\section{Access}

The Materials Design Platforms provide access to utilize computational tools implemented in the platforms. All activities are available within a network-wide web-based interface, and users can even execute materials simulations within allowed computational resources and regulations.

\section{Intellectual Property Terms}

A standard intellectual property (IP) policy of the NRF has been adopted to all research institutes in Korea. Thus, the policy is also applied to the materials design platforms. Many factors should be considered for the ownership of a specific IP. However, one generally accepted guideline is that all the IPs generated during the projects belong to the institutes for which the researchers are working. If an external collaborator contributes to the development of the IP, the IP is shared with the institutes of the external collaborator.

\section{Data (ownership and sharing)}

Ownership of data generated by use of the materials design platform is exclusively applied to the generator.

\section{Public Private Collaboration}

The platform is open to not only the public but also the private sector. It is expected that the platform is to leverage the collaboration between academy and industry. In addition, the materials design platform itself results from the public-private collaborations.

\section{Education}

Regular user workshops and showcases haven been held for each platform during development. 


\section{Measures of activity}

The platforms are still in the development stage. The platform activity is planned to be measured and reported on the basis of the log data of the platform (user access, software download, data download, etc.). The number of citation from research literatures (research papers, research report, and so on) can also be a scale to measure the activity of the platform.

\section{Stage of research, development, or commercialisation}

Two thematic platforms are open to service ${ }^{4}$. However, it must be pointed out that the platforms mostly generated and managed pre-competitive data, and that the materials design platforms are in the development stage. In addition, based on the platform technology, one start-up company was established in $2016^{5}$.

\section{Safety/regulation}

There is no significant safety issue on the materials design platform, except the safety regulations for the HPC server maintenance facility.

\section{Societal Implications}

The platforms would contribute to the nanotechnology development by providing an easyto-use computation environment. This will improve the efficiency of R\&D in nanotechnology and thus will enable Korean society to understand the significance of materials design by high-performance computation.

\section{Converging Technologies}

Materials design platform development enhances the collaboration between various disciplines from materials science, chemistry, physics, computer engineering, machine learning and data science.

\section{Summary Statement}

Materials design platforms provide virtual research spaces to accelerate nanotechnology industrialization, and promote the new materials development with advanced tools based on both experiments and computations. National R\&D Data Infrastructure provides a hierarchical data framework (1) to promote sharing and utilization of research data generated and accumulated nationwide so that scientific breakthrough in materials development is feasible by data-driven research and development.

\section{References}

1. Strategy for Nanotechnology Industrialization (2015.4.30, MSIT, MOTIE and ME).

2. PACST Report, Proposal for Strategic Development Policy of Value-added Materials leading to New Industries, p120 (PACST, 2016.2.5, 12-B553051-000031-01).

3. Plan for Managing Materials R\&D Data (2017.9.15, MSIT).

4. http://vfab.org

5. http://virtuallab.co.kr/en/ 


\section{United States of America: National Nanotechnology Coordinated Infrastructure} (NNCI)

\section{Platform Name and Description.}

The National Nanotechnology Coordinated Infrastructure (NNCI) is a network of user facilities funded by the National Science Foundation (NSF). There are 16 NNCI nodes at academic institutions and 13 partner organization sites that provide access to nanofabrication and characterization facilities. The NNCI sites are located in 17 states across the country and involve a total of 29 university and partner organizations. The NNCI provides access to leading-edge fabrication and characterization tools, instrumentation, as well as scientific expertise that spans a wide variety of disciplines related to nanoscale science, engineering, and technology. Collectively, the NNCI sites provide access to 69 distinct facilities with more than 2000 tools. The coordinating office is located at Georgia Tech in Atlanta GA. This office is tasked with enhancing the impact of NNCI sites as a national network of user facilities and establishing a web portal to link the individual facilities' websites to provide a unified entry point to the user community of overall capabilities, tools and instrumentation.

\section{Parent Policy Initiative}

The National Nanotechnology Initiative was signed into law with the 21st Century Nanotechnology Research and Development Act (P.L. 108-153). The Act directs the President to implement a National Nanotechnology program and requires that program's activities to include: "establishing a network of advanced technology user facilities and centers." 13 The NNCI is one of two user networks supporting nanotechnology research and development. The other network consists of 5 Nanoscale Science Research Centers housed in National Laboratories supported by the Department of Energy ${ }^{14}$. The National Nanotechnology Initiative (NNI) is a U.S. Government research and development (R\&D) initiative involving the nanotechnology-related activities of 20 departments and independent agencies, with a range of research and regulatory roles and responsibilities. Funding support for nanotechnology R\&D stems directly from NNI member agencies.

\section{Stated Aim or Mission}

"The goal of the NNCI network is (1) to provide open access to state-of-the-art nanofabrication and characterization facilities, their tools and staff expertise across the US, and (2) to use network resources to support education and outreach, as well as societal and ethical implications programs in/of nanotechnology."1

\section{Funding}

NSF provides a total of $\$ 81$ million over a five-year period ( $\sim \$ 16.2$ million/year) to support $16 \mathrm{NNCI}$ sites and a coordinating office. The sites are funded at between $\$ 500,000$ and $\$ 1.6$ million each, per year. For year 3 of the network (October 1, 2017 -September 30, 2018 ), the network collected a total of $\$ 40.5$ million in user fees. Individual sites may also have funding from their institutions and/or localities. The NNCI leveraged significant cost

13 21st Century Nanotechnology Research and Development Act (P.L. 108-153) https://www.govinfo.gov/content/pkg/PLAW-108publ153/pdf/PLAW- 108publ153.pdf

${ }^{14}$ Nanoscale Science Research Centers, U.S. Department of Energy, https://nsrcportal.sandia.gov/ 
share in the second and third years for acquisition of equipment by more than 86 to 1 for contributions from university funds, grants, industry, or other sources compared to use of NNCI funds.

\section{Access}

The network provides access to fabrication and characterization facilities for researchers from universities, industry and government. Specific procedures and policies vary between sites, but a network-wide web-based interface, called a new user gateway, collects basic information regarding tool or technique required and geographic preference. A representative from one of the relevant sites will follow up on the request to gather more information regarding the specific need and discuss terms regarding timing, fees required, training, and other details. The NNCI network staff often collaborate to identify the best options based on the nature of the request.

\section{Intellectual Property Terms}

There is no network-wide intellectual property (IP) policy and NNCI sites adopt IP policies of their parent university. The sites are encouraged to avoid IP entanglement or cases where ownership is unclear. The ownership of specific IP may depend on several factors governed by the host university policy including where work was performed and if done by staff or by the external user, whether staff contributed significantly to the development of the IP, and whether the user is an academic or industry partner. The sites track IP from disclosure to licensing as means as a partial measure of return on investment. For 2017, the users and sites reported 486 patents, patent applications, and invention disclosures network-wide.

\section{Data (ownership and sharing)}

Ownership of data generated by use of the NNCI facilities is maintained by the user.

\section{Public Private Collaboration}

The NNCI as a platform is funded by the Federal government and is not the result of a public-private collaboration. Individual research and development projects enabled by the user facilities, however, can result in or be the basis of such collaborations. In year 4, the private sector accounted for $14.7 \%$ of NNCI network users (1,961 users) and $14.8 \%$ of user hours. Several individual sites report on specific collaborations with small and large companies and several small companies have indicated access to these facilities was critical to their success.

\section{Education}

Education and workforce development is a critical component of the NNCI with the mission of these efforts "to offer education and training to address the growing need for a skilled workforce and informed public; provide resources, programs, and materials to enhance knowledge of nanotechnology and its application to real-world issues; and support the US economy by enabling a STEM-literature workforce ready to meet the technological challenges of a nano-enabled economy as well as an informed citizenry that supports continued and safe growth of nanotechnologies" 1 . In the management structure, one of the three associate directors is focused on Education and Outreach (E\&O), and each of the 16 sites has an E\&O coordinator. Furthermore, two of the network-wide working groups are focused in this area: K-12 and Community Outreach Working Group and Workforce Development and Community Colleges Working Group. 


\section{Measures of activity}

The NNCI collects and reports on a variety of categories to measure activity. The following bullets show categories of information for the entire network, according to the NNCI annual report. ${ }^{12}$

- Number of platform sites and partners: 16 sites, 13 partners

- Tools and equipment available: 2,000 tools in 69 facilities

- Number of users in fiscal year 2017:

○ Total unique facility users: 13,110

○ Number of industry users: 1,870

○ Number of government and non-profit users: 65

○ Foreign users: 79

- New users trained: 4,981

- Facility hours: $1,006,764$

- Papers published, patents calendar year 2017

○ Papers: 2965

○ Presentations: 1398

○ Books and book chapters: 38

○ Patents/Applications/Invention Disclosures: 486

\section{Stage of research, development, or commercialisation}

The role of the NNCI network is to enable and support cutting-edge research required by the user community for the user's unique need. The NNCI network services a broad range of stages along the technology development pathway. Based on user statistics, the bulk of the users are conducting research, but industry users are likely conducting applied research and development.

\section{Safety and regulation}

Every site has a staff member responsible for safety and the network has a working group for Environmental Health and Safety (EHS). The EHS working group is concerned with a myriad of safety and health concerns including facility safety, emergency equipment and response, chemical safety and waste handling incident response and incident reporting procedures and site-specific training. As lab safety is an important skill set for the nanotechnology workforce, the NNCI network is addressing this need at each site.

\section{Societal Implications}

One of the four goals of the NNI is responsible development of nanotechnology that includes both the environmental, health and safety aspects of nanotechnology, as well as the potential ethical, legal, and societal implications. The NNCI has recognized the need to think about the impacts of nanotechnologies as they are discovered, developed and implemented. The Associate Director for Societal and Ethical Implication (SEI) of the 
Coordinating Office has worked to help all of the NNCI sites develop SEI research and engagement programs.

\section{Converging Technologies}

An objective of the network is to develop a clear vision for how it supports other national research priorities such as artificial intelligence, quantum, and medical innovation, and how it can evolve and address these and other areas going forward.

\section{Summary Statement}

The NNCI sites serve as epicenters to collaborative ecosystems in their regions. Bringing together faculty, students, researchers, industry, and the business development community from a wide variety of disciplines creates an atmosphere of collaboration where these areas converge. The cutting-edge tools and expertise to fabricate and characterize materials and devices pushes the boundaries of technology areas as diverse as electronics to medicine. 


\section{Endnotes}

${ }^{1}$ For more information see:NNCI Coordinating Office Annual Report (Year 3) Submitted February 8, 2019. Accessible online: https://www.nnci.net/sites/default/files/inlinefiles/NNCI\%20CO\%20Annual\%20Report\%202019\%20Web_0.pdf

${ }^{2}$ https://www.nsf.gov/od/oia/convergence/index.jsp

${ }^{3}$ https://nanoearth.ictas.vt.edu/index.html

${ }^{4}$ https://scaletravels.inl.int/

${ }^{5}$ For more information see:Senate Committee on Energy, Environment, and Natural Resources, May 2018.

https://sencanada.ca/content/sen/committee/421/ENEV/reports/ENEV_OilGas_FINALweb_e.pdf

${ }^{6}$ For more information see: Pan-Canadian Framework on Clean Growth and Climate Change. https://www.canada.ca/en/services/environment/weather/climatechange/climate-plan.html

${ }^{7}$ For more information see: Eunjung Shin, Korean Case Report on Enhanced Access to Public Data for Science, Technology and Innovation (OECD Case Report, 2018).

${ }^{8}$ https://www.nims.go.jp/MII-I/en/

${ }^{9}$ See http://nano.vfab.org

${ }^{10}$ See http://battery.vfab.org

${ }^{11}$ See http://qcat.vfab.org

12 For more information see: National Nanotechnology Coordinated Infrastructure, NNCI Coordinating Office Annual Report (Year 3) Submitted February 8, 2019. https:/www.nnci.net/sites/default/files/inline-

files/NNCI\%20CO\%20Annual\%20Report\%202019\%20Web_0.pdf 